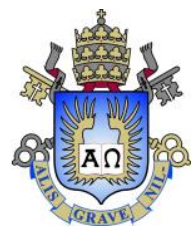

Guilherme Coppi Durante

\title{
A Utilização de Blockchain para controle da cadeia de distribuição de combustíveis derivados: Proposta de modelo de negócio
}

Dissertação de Mestrado

Dissertação apresentada como requisito parcial para obtenção do grau de Mestre pelo Programa de PósGraduação em Administração de Empresas do Departamento de Administração da PUC-Rio

Orientador: Prof. Leonardo Gomes Lima 
Guilherme Coppi Durante

\section{A Utilização de Blockchain para controle da cadeia de distribuição de combustíveis derivados: Proposta de modelo de negócio}

Dissertação de Mestrado

Dissertação apresentada como requisito parcial para obtenção do grau de Mestre pelo Programa de PósGraduação em Administração de Empresas do Departamento de Administração da PUC-Rio Aprovada pela Comissão Examinadora abaixo.

Prof. Leonardo Gomes Lima Orientador Departamento de Administração - PUC-Rio

Prof. Carlos de Lamare Bastian Pinto Departamento de Administração - PUC-Rio

Profa. Cristina Pimenta de Mello Spineti Luz Faculdade de Administração e Ciências Contábeis - UFRJ 
Todos os direitos reservados. É proibida a reprodução total ou parcial do trabalho sem a autorização da universidade, do autor e do orientador.

\section{Guilherme Coppi Durante}

Engenheiro Mecânico formado pela UNICAMP (Universidade Estadual de Campinas), Mestre em Engenharia pela Ecole Centrale de Lille e técnico em Mecatrônica pela ETEGV (Escola Técnica Estadual Getúlio Vargas).

Possui background no setor de Óleo de Gás em Gestão de Projetos, Execução de Projetos de Engenharia e Investimentos em Infraestrutura de Distribuição.

Ficha Catalográfica

Durante, Guilherme Coppi

A utilização de Blockchain para controle da cadeia de distribuição de combustíveis derivados: proposta de modelo de negócio / Guilherme Coppi Durante ; orientador: Leonardo Gomes Lima - 2021.

65 f. : il. color. ; $30 \mathrm{~cm}$

Dissertação (mestrado) - Pontifícia Universidade Católica do Rio de Janeiro, Departamento de Administração, 2021.

Inclui bibliografia

1. Administração - Teses. 2. Blockchain. 3. Distribuição de combustíveis. 4. Óleo e gás. 5. Smart contracts. 6. Cadeia de suprimentos. I. Lima, Leonardo Gomes. II. Pontifícia Universidade Católica do Rio de Janeiro. Departamento de Administração. III. Título

CDD: 658 


\section{Agradecimentos}

Ao meu orientador Professor Leonardo Gomes Lima pelo enorme conhecimento compartilhado acerca da tecnologia da Blockchain, pela provocação, incentivo e confiança no desenvolvimento deste projeto de pesquisa e por todas as orientações e trocas durante a elaboração deste trabalho. Sem a sua dedicação e suporte, este trabalho não teria sido possível.

À minha esposa, amiga, confidente e parceira de luta Larissa Souza, pelo seu incondicional apoio, paciência e compreensão durante todo o processo do Mestrado.

Aos meus pais e irmãos que mesmo a quilômetros de distância seguem exercendo um papel fundamental de motivação e apoios em todas as etapas e decisões da minha vida.

Aos meus colegas de turma pelas ricas trocas em sala de aula e fora dela, pelo incentivo constante e pelo convívio harmonioso que trouxe leveza durante todo o Mestrado.

O presente trabalho foi realizado com apoio da Coordenação de Aperfeiçoamento de Pessoal de Nível Superior - Brasil (CAPES) - Código de Financiamento 001. 


\section{Resumo}

Durante, Guilherme Coppi; Lima, Leonardo Gomes. A Utilização de Blockchain para controle da cadeia de distribuição de combustíveis derivados: Proposta de modelo de negócio. Rio de Janeiro, 2021. 65p. Dissertação de Mestrado - Departamento de Administração, Pontifícia Universidade Católica do Rio de Janeiro.

Os problemas relacionados ao controle de qualidade e a fraudes no setor de distribuição de combustíveis são tão antigos quanto o próprio setor. Furto, desvios de qualidade, sonegação fiscal e adulteração de combustíveis são problemas recorrentes e muito prejudiciais para toda a cadeia. Na tentativa de combater estes desvios, as distribuidoras continuamente empenham esforços e recursos financeiros no desenvolvimento de novos procedimentos operacionais e mecanismos de governança. Tais mecanismos de governança visam reduzir o espaço para oportunismo dos envolvidos e aumentar o controle sobre os produtos ao longo da cadeia. Neste contexto, a Blockchain tem se provado uma eficiente tecnologia para a implantação de mecanismos de governança e para o controle de cadeias de suprimentos. Através do uso de contratos inteligentes executados em uma Blockchain privada, este trabalho propõe um modelo de negócio de uma solução tecnológica para o controle da cadeia de suprimentos de combustíveis. Esta solução visa o rastreamento e certificação do volume vendido, desde a distribuidora até o consumidor final, através de pares digitais refletidos na Blockchain. Com isso, pretende-se garantir um controle pleno das distribuidoras sobre a cadeia de suprimentos.

\section{Palavras-Chave}

Blockchain; Distribuição de combustíveis; Óleo e Gás; Smart Contracts; Cadeia de suprimentos 


\section{Abstract}

Durante, Guilherme Coppi; Lima, Leonardo Gomes (Advisor). The Use of Blockchain for Controlling the Oil \& Gas Supply Chain: A Business Model Proposal. Rio de Janeiro, 2021. 65p. Dissertação de Mestrado Departamento de Administração, Pontifícia Universidade Católica do Rio de Janeiro.

Problems related to quality control and fraud in the fuel distribution sector are as old as the sector itself. Fuel theft, tax evasion and adulteration are recurrent events and very damaging for the entire industry. In an attempt to suppress these deviations, distributors continually commit efforts and financial resources to the development of new operating procedures, new technologies and new governance mechanisms. Such mechanisms aim to reduce the opportunism and to increase control over products throughout the supply chain. In this context, Blockchain has proven to be an efficient technology for the implementation of governance mechanisms and for the control of supply chains. Through the use of smart contracts executed on a private Blockchain, this work proposes a business model of a technological solution for controlling the volumes being transferred through the fuel supply chain. The proposed solution, presented in the form of a business model, aims to track and certify the volume sold, from the distributor to the final costumer through tokenized digital pairs reflected in a Blockchain. With so, it is intended to guarantee full control of the distributors over the supply chain.

\section{Keywords}

Blockchain; Downstream; Oil and Gas; Smart Contracts; Supply Chain 


\section{Sumário}

1 Introdução 12

2 Blockchain: The Trust Machine 15

$\begin{array}{lll}2.1 & \text { O Bloco } & 17\end{array}$

2.1.1 O mecanismo de consenso 20

2.2 DLT: Distributed Ledger Technology 20

2.3 Principais Características de uma Blockchain 21

2.3.1 Descentralização 21

$\begin{array}{lll}2.3 .2 & \text { Imutabilidade } & 21\end{array}$

2.3.3 Transparência 22

2.3.4 Eficiência 22

2.3.5 Segurança 22

2.4 A Evolução das Blockchains 22

2.4.1 Blockchain 1.0: Moeda 23

2.4.2 Blockchain 2.0: Contratos 23

2.4.3 Blockchain 3.0: Além de Moedas e Contratos 24

2.5 Os tipos de Blockchain 25

2.5.1 Blockchain pública 26

2.5.2 Blockchain privada 26

2.5.3 Blockchain em consórcio 26

$\begin{array}{lll}2.6 & \text { As Blockchains Privadas } & 27\end{array}$

$\begin{array}{lll}2.7 & \text { Os Smart Contracts } & 27\end{array}$

2.8 O HyperLedger 28

$\begin{array}{lll}2.9 & \text { Referencial Teórico } & 29\end{array}$

3 O Mercado de Distribuição de Combustível 31

3.1 Do Poço ao Posto: Um Panorama Geral 31

3.2 Upstream, midstream e downstream 32

3.3 Da Distribuidora ao Cliente Final 33 
$4 \quad$ Novo Modelo de Negócio de Distribuição de Combustíveis em Blockchain

4.1 Escolha da Blockchain 38

4.1.1 O HyperLedger Fabric 41

4.2 Membros participantes e permissões 42

4.2.1 A distribuidora 42

4.2.2 O transportador 43

4.2.3 O revendedor 44

4.2.4 O consumidor final 45

4.3 Fluxo operacional 46

4.3.1 Bloco 1- Demanda/Suprimento 48

4.3.2 Bloco 2 - Logística 49

4.3.3 Bloco 3 - Balanço de volume e qualidade 51

4.3.4 Bloco 4 - Venda ao consumidor final 53

4.4 O recebimento do produto - o ponto sensível 54

4.5 O balanço de tokens $\quad 55$

4.6 Transparência e incentivo - gerando engajamento 56

4.7 Por que este modelo é mais eficiente?

5 Conclusão 60

5.1 Recomendações para futuros trabalhos 62

6 Referências bibliográficas 63 


\section{Lista de Figuras}

Figura 1 - Esquema de uma blockchain "B" composta por 4 blocos e 9 transações (Fonte: Hyperledger, 2020a)

Figura 2 - Esquema típico de um bloco (Fonte: Hyperledger, 2020a) 18

Figura 3 - Detalhes típicos do registro de uma transação (Fonte: Hyperledger, 2020a)

Figura 4 - Tecnologias presentes no guarda-chuva do projeto Hyperledger (Fonte: Hyperledger, 2020b)

Figura 5 - Cadeia de abastecimento (Fonte: Empresa De Pesquisa Energética - EPE, 2018)

Figura 6 - Cadeia de valor do setor de óleo e gás

(Fonte: Lu et al., 2019)

Figura 7 - Esquema simplificado do fluxo operacional de distribuição (Fonte: Elaboração própria e Empresa De Pesquisa Energética EPE, 2018)

Figura 8 - Fluxograma para escolha do tipo de blockchain segundo aplicação Fonte: elaboração própria, CAICT (2018) e Lu et al. (2019)

Figura 9 - Fluxograma completa do processo de venda de combustível da distribuidora até o consumidor final. (Fonte: Elaboração própria) Elabora com a ferramenta Bizagi Modeler versão 3.8.0.179 


\section{Lista de Tabelas}

Tabela 1 - Tipos de Blockchain

(Behnke; Janssen, 2020; Lu Et Al., 2019; Pahl; El loini; Helmer, 2018) 25 


\section{Lista de Abreviaturas}

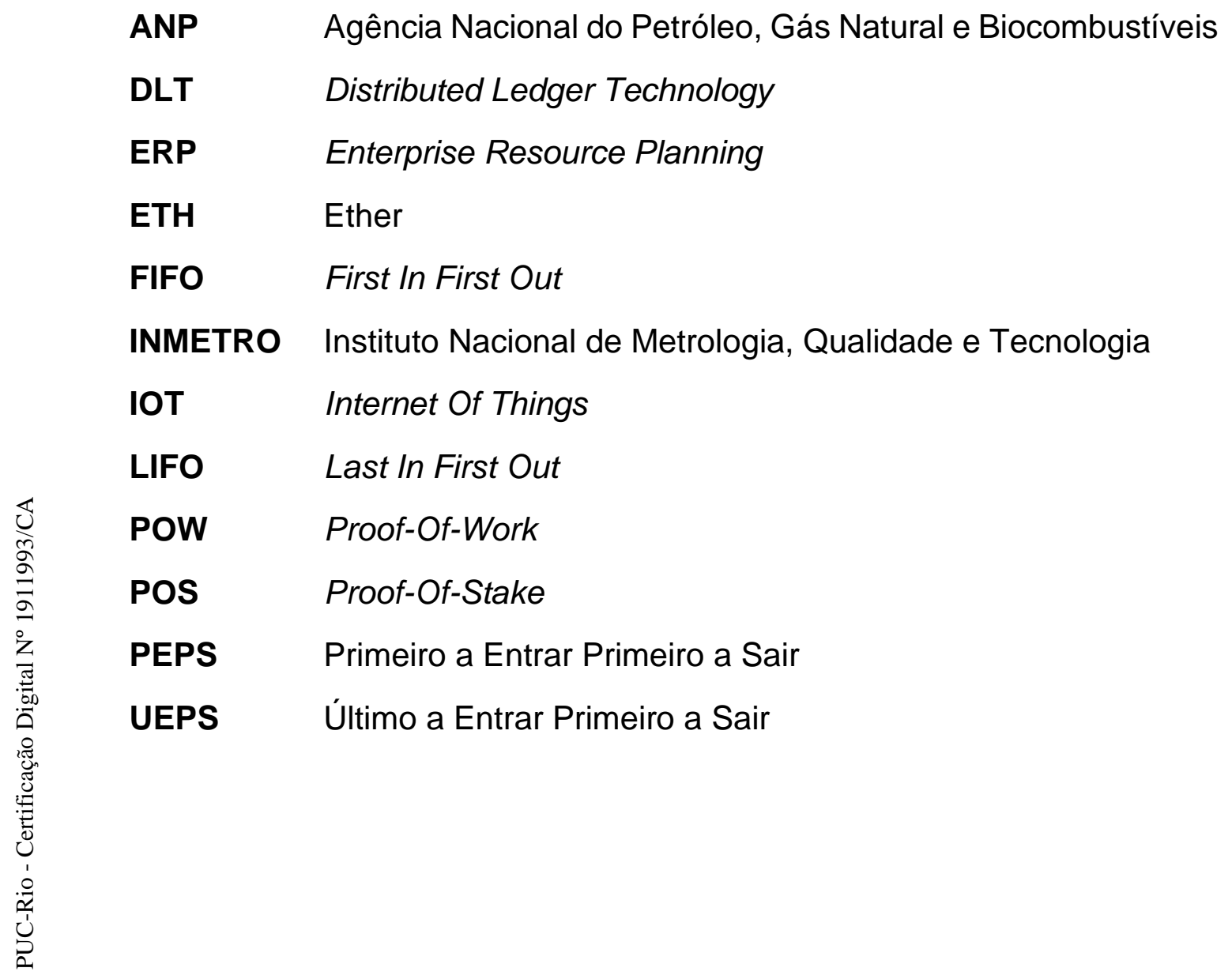




\section{1 \\ Introdução}

Os problemas relacionados ao controle de qualidade e a fraudes no setor de distribuição de combustíveis são tão antigos quanto o próprio setor. Notícias sobre furtos de combustível, desvios de qualidade, sonegação fiscal e adulteração de produtos e equipamentos de medição são frequentes nos noticiários. Estes desvios têm impactos em toda a cadeia de distribuição, desde a produção, estocagem, transporte e até a comercialização no posto de combustíveis. Os impactos mais evidentes à sociedade estão relacionados à segurança da operação, à confiança generalizada na cadeia e, principalmente, aos custos envolvidos de transação. O combate às fraudes exige do setor maior controle operacional, uma robusta estrutura legal e de fiscalização, equipamentos cada vez mais sofisticados, entre outros. Todo este aparato visa aumentar a governança sobre as transações e assim minimizar perdas e trazer maior confiança entre os participantes e ao próprio mercado consumidor. Os custos destas estruturas de governança, entretanto, são distribuídos ao longo da cadeia e acabam sendo pagos pela sociedade, nos preços dos combustíveis.

Uma estrutura robusta de governança sobre os contratos permite uma maior transparência nas transações, uma redução dos riscos e incertezas, um mapeamento maior sobre as diversas variações possíveis nas condições negociadas e, consequentemente, menor espaço para oportunismos. Estas estruturas estão presentes nas relações de compra, venda e transporte na cadeia de distribuição e podem se manifestar através de cláusulas contratuais, uso de equipamentos de medição, condições operacionais restritivas e até fiscalizações periódicas aos postos de combustíveis.

Quando estamos falando sobre governança de contratos e transações, podemos destacar uma tecnologia relativamente recente, apresentada em 2008, que permitiu uma revolução na maneira como os contratos digitais são estabelecidos e executados, a Blockchain. A Blockchain é uma plataforma tecnológica em rede capaz de garantir a segurança de transações digitais. Sua estrutura permite a criação de um único e inalterável registro de transação entre duas entidades, que fica disponível na rede para consulta e validação a qualquer 
momento. A estrutura da Blockchain é elaborada de tal maneira que se torna praticamente impossível a sua violação ou a alteração de dados de transações registradas. Por estes motivos, o uso de Blockchain tem se popularizado e impulsionado o surgimento de aplicações que fazem uso de sua tecnologia em contextos que necessitem de elevados padrões de segurança, como moedas digitais, sistemas de transações bancárias, sistemas de registros de imóveis e propriedades, e contratos virtuais. De maneira simplificada, a Blockchain é uma plataforma digital segura e inalterável de registro de transações.

Uma das aplicações da tecnologia da Blockchain foi no desenvolvimento de contratos digitais seguros e autoexecutáveis, conhecidos como smart contracts. Os smart contracts permitem a celebração de contratos seguros, transparentes, verificáveis em tempo real e cuja execução seja atrelada diretamente ao cumprimento de suas cláusulas. Estes contratos reduzem a ambiguidade e incertezas existentes nas relações contratuais, e trazem maior confiança para as contrapartes envolvidas.

Além desta aplicação, a tecnologia da Blockchain permite a utilização de seus registros como livro-razão permanente e digital, capaz de registrar propriedade de ativos físicos através dos chamados pares digitais, ou tokens. Os mais diversos tipos de ativos físicos podem ser registrados e transacionados através de seus pares digitais em aplicações desenvolvidas sobre a tecnologia da Blockchain. Alguns exemplos estão no registro de propriedade de imóveis, obras de arte, diamantes e até no rastreamento da cadeia de suprimento de alimentos, exploração de commodities e transporte de bens duráveis. A versatilidade da tecnologia permitiu com que sua utilização fosse extrapolada da função original de pagamentos digitais para, virtualmente, qualquer transação virtual ou física.

Neste contexto, o presente trabalho pretende propor um modelo de negócio de uma solução tecnológica baseada em Blockchain capaz de melhorar a governança sobre o processo de venda e distribuição de combustíveis e de, consequentemente, reduzir as possiblidades de fraude existentes na cadeia. A solução estudada pretende possibilitar o rastreio do produto transacionado desde a origem, nas Bases de Distribuição, até o consumidor final, no posto de combustíveis. A solução pretende adotar um registro virtual (token) do combustível comercializado que poderá certificar o volume transacionado ao longo de toda a cadeia, passando, inclusive, pelos intermediários retalhistas e transportadores. Ou seja, pretende-se criar um controle volumétrico com certificado digital em Blockchain capaz de garantir que o mesmo volume originalmente emitido pelo distribuidor chegará ao consumidor final. No ato do abastecimento, o consumidor 
receberá, além do volume físico de combustível atestado pelo medidor do posto, um certificado digital de mesma ordem de grandeza atestando que o volume comprado efetivamente foi emitido pelo distribuidor autorizado. No caso de qualquer adulteração ou furto de volumes pela cadeia, os intermediários e o consumidor final poderão perceber um descasamento entre os certificados digitais e o volume efetivamente comercializado.

Este certificado digital entregue ao consumidor final deverá ter um valor comercial, possibilitando o cliente converter a sua contribuição para a verificação das informações sobre o produto em benefício próprio. Além disso, o balanço e a distribuição dos certificados digitais ficarão registrados na Blockchain sob responsabilidade da distribuidora, assim ela poderá manter um controle preciso quanto ao volume entregue e vendido pelos postos de combustíveis.

Com esta solução, pretende-se reduzir drasticamente as possiblidades de furtos e adulterações na cadeia de distribuição, reduzindo os custos de transação para os distribuidores, intermediários e, finalmente, para o consumidor final.

Na próxima seção, "Blockchain: The Trust Machine", será apresentado o funcionamento geral da tecnologia da Blockchain e sua aplicação para a elaboração dos smart contracts, função central da solução proposta por este trabalho. Na seção seguinte, "O Mercado de Distribuição de Combustível", será apresentado um panorama sobre a indústria do petróleo no Brasil, dando-se maior destaque para a cadeia de distribuição do produto acabado, das bases até o consumidor final. A seção chamada "Novo Modelo de Negócio de Distribuição de Combustíveis" apresenta, finalmente, a aplicação proposta da Blockchain para a melhoria da governança sobre a cadeia de distribuição de combustíveis, solução que visa reduzir significativamente as possiblidades de oportunismo dos participantes da cadeia, tornando o processo mais transparente e seguro para todos os envolvidos. Na sequência, a "Conclusão" apresenta um resumo sobre os benefícios da solução proposta e traz algumas discussões sobre sua adoção. No último capítulo, serão sugeridos temas para aprofundamento e continuidade da solução proposta neste trabalho. 


\section{2 \\ Blockchain: The Trust Machine}

Uma Blockchain é uma plataforma digital pública e descentralizada de "livro de registros" de transações (Evans, 2014). Como o nome sugere, esta plataforma se organiza através do encadeamento constante e ordenado de forma temporal de novos blocos de transações (Nakamoto, 2008). Sua operacionalização se apoia em uma rede de nós descentralizados de processamento que garantem tanto a continuidade do crescimento da Blockchain, através da inclusão de novos blocos, como a validação consensual da legitimidade da cadeia que está construída.

Seu conceito veio a público em um trabalho seminal publicado em 2008 sob o pseudônimo de Satoshi Nakamoto, com a finalidade de eliminação de problemas de cobranças duplicadas em transações financeiras digitais, através da criação de uma plataforma descentralizada de validação e consenso, incentivada com uma criptomoeda conhecida como Bitcoin. O conceito da Blockchain coloca a transação como unidade central da solução (Treiblmaier, 2018) e estabelece mecanismos de segurança que garantam a validade da transação através de uma estrutura distribuída e não hierárquica de verificação, conhecida como DLT (Distributed Ledger Technology). Tal estrutura distribuída de validação e inclusão de blocos dispensa a necessidade de autoridades/instituições centralizadas de acreditação, como bancos, governos e cartórios (Nakamoto, 2008; Raval, 2016),

e fortalece os mecanismos de confiança das transações através da democratização da informação para as contrapartes (Chen, 2018)

Operacionalmente, cada transação digital é registrada em um bloco de transações e, uma vez validada pelo consenso coletivo da Blockchain, é incluída na cadeia de blocos existente e passa a se tornar permanente, inalterável e publicamente acessível (Treiblmaier, 2018). A sustentação desta estrutura, como proposto originalmente por Nakamoto, é garantida através dos mineradores, que são nós da rede que fornecem capacidade de processamento (na forma de CPU) em troca de uma recompensa em uma criptomoeda, no caso, o Bitcoin.

As transações digitais que são registradas na Blockchain podem representar transferências financeiras, mas também qualquer transferência de 
informações. Esta característica permitiu a extrapolação da finalidade original da Blockchain - segurança em transferências monetárias digitais - para o registro de transações de quaisquer ativos (Tapscott; Tapscott, 2016), por meio de chamados smart contracts ou smart properties. Estes contratos inteligentes, também conhecidos como ativos tokenizados (Seijas; Thompson; Mcadams, 2016; Zhao; Fan; Yan, 2016), são protocolos digitais em uma Blockchain que executam termos de um contrato entre uma ou diversas partes (Szabo, 1997). Estes contratos, por serem digitais e estarem apoiados em uma estrutura distribuída de validação, dispensam, teoricamente, a necessidade de uma estrutura externa de governança e validação (Schmidt; Wagner, 2019), e garantem a execução automática e a dispensa de intermediários através de regras pré-estabelecidas na blockchain (Savelyev, 2017).

Além dos contratos inteligentes, esta tecnologia permite a criação dos chamados "gêmeos digitais", que são registros digitais de ativos reais que podem servir tanto para o rastreio quanto para a atestação (pública, acessível e digital) de propriedade dos ativos subjacentes.

Como apresentado por Davidson; De Filippi; Potts (2016), a Blockchain é, portanto, uma nova tecnologia institucional que possibilita novos tipos de contratos e organizações, ou seja, estruturas e instituições alternativas de governança. Ela elimina, ou inibe, o comportamento oportunista através de uma transparência publica radical das transações associada aos mecanismos de criptografia e consenso coletivo, e da execução dos smart contracts. Ou seja, ela possibilita o estabelecimento de um novo tipo de coordenação socioeconômica entre as empresas, indivíduos e instituições.

Através da democratização de acesso às informações e da significativa redução dos custos de transação, a Blockchain estabelece um mecanismo de confiança nas contrapartes envolvidas (Chen, 2018). Por este motivo, a revista The Economist em matéria de 2015 intitula a Blockchain de The Trust Machine, uma tecnologia que permite com que indivíduos que não necessariamente confiam um no outro possam colaborar sem a necessidade de uma autoridade central mediadora (The Economist, 2015). 


\section{1 \\ O Bloco}

O bloco é a unidade básica de construção de uma blockchain. $O$ crescimento e organização desta se dá através do encadeamento sucessivo e criptográfico de blocos de transações. Diversas transações eletrônicas são agrupadas em um bloco que, após ser revisado e validado de forma consensual pelos demais usuários da rede, será inserido ao final da cadeia já existente (Swan, 2015). Uma transação representa uma atualização ou declaração de estado de algum objeto físico ou digital, podendo ser uma transferência financeira, o registro de uma propriedade, a autenticação de um documento, o status de um usuário, entre outros.

O encadeamento dos blocos acontece através de uma sequência cronológica transparente e distribuída de hashs criptografados de assinaturas digitais, cada novo bloco possui um endereço próprio e tem como propriedade o endereço do bloco predecessor (Da Silva Momo; Schiavi; Behr, 2018). Desta forma, a qualquer momento, a cadeia pode ser mapeada diretamente até o bloco original, também conhecido como bloco gênese.

Tal mecanismo criptográfico e organização faz com que, uma vez registrada na blockchain, uma transação não possa mais ser removida ou alterada (Nakamoto, 2008). Uma eventual tentativa de alteração em uma transação já incluída na blockchain não seria aprovada pelo mecanismo de consenso da rede, o que automaticamente mataria o falso bloco e a tentativa de adulteração.

Na Figura 1 pode-se visualizar um esquema típico de organização de uma blockchain com o encadeamento de 4 blocos, sendo o primeiro deles (B0) o bloco gênese. Cada bloco (B) possui um conjunto (D) criptografado de registro de transações $(T)$ e um header $(H)$ que contém o registro de seu próprio endereço e o registro do endereço do seu bloco predecessor. Desta forma, os blocos estão intrinsicamente ligados na composição da blockchain. 


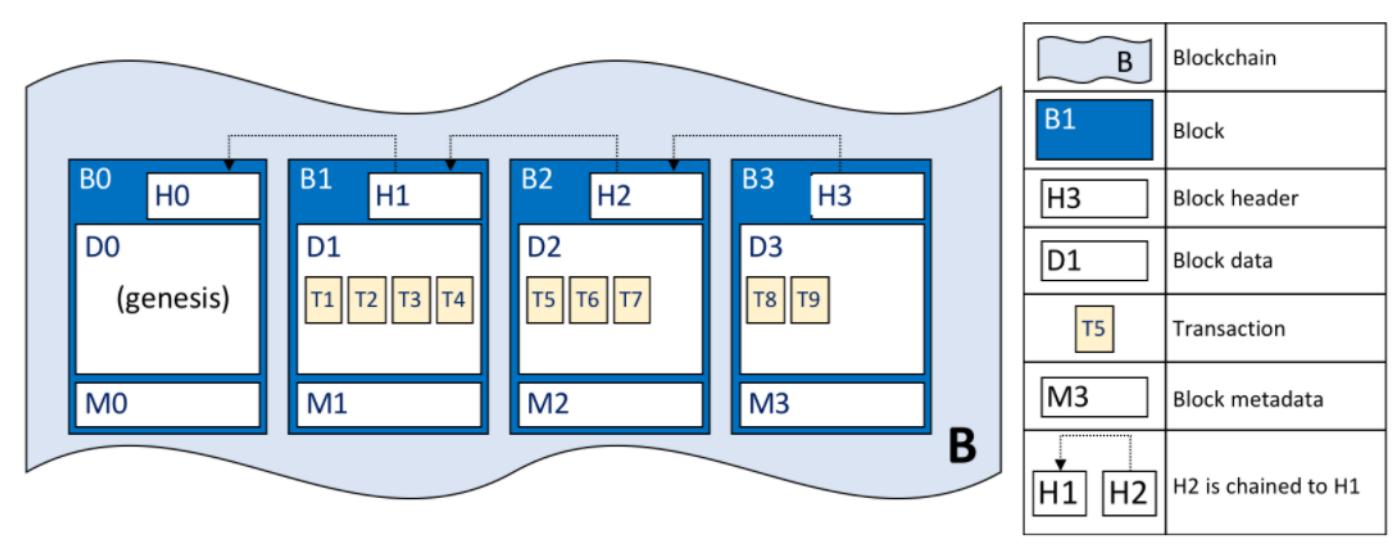

Figura 1 - Esquema de uma blockchain "B" composta por 4 blocos e 9 transações (Fonte: Hyperledger, 2020a)

A Figura 2 representa em maior detalhe a estrutura de um bloco típico de uma blockchain. O bloco (B2) contém um conjunto (D2) de transações (T5, T6 e T7), um conjunto de metadados (M2) e um header ( $\mathrm{H} 2)$. O header $(\mathrm{H} 2)$, por sua vez, armazena o número do boco (2), um hash das transações pertencentes ao próprio bloco $(\mathrm{CH} 2)$ e uma cópia do hash do bloco predecessor $(\mathrm{PH} 1)$.

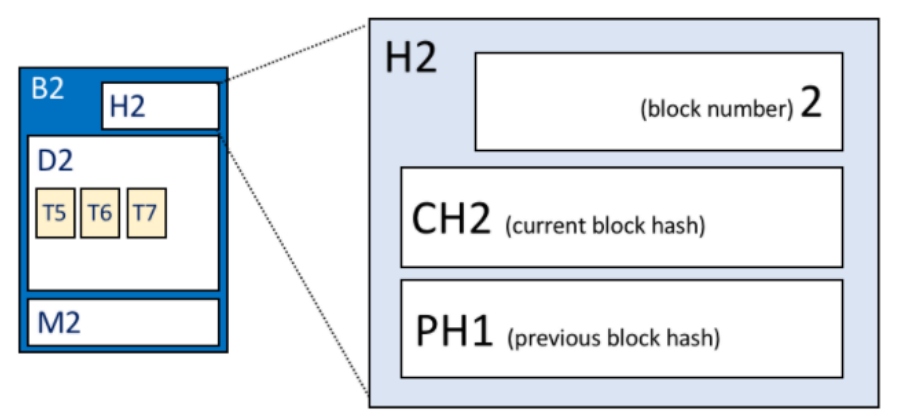

\begin{tabular}{|c|c|}
\hline $\mathrm{H} 2$ & Block header \\
\hline 2 & Block number \\
\hline $\mathrm{CH} 2$ & $\begin{array}{l}\text { Hash of current block } \\
\text { transactions }\end{array}$ \\
\hline $\mathrm{PH} 1$ & $\begin{array}{l}\text { Copy of hash from } \\
\text { previous block }\end{array}$ \\
\hline $\mathrm{H}_{2} \mathrm{~V} 2$ & $\mathrm{~V} 2$ is detailed view of $\mathrm{H} 2$ \\
\hline
\end{tabular}

Figura 2 - Esquema típico de um bloco (Fonte: Hyperledger, 2020a)

Finalmente, a Figura 3 representa em maior detalhe a estrutura de informações contidas em um registro de transação. 


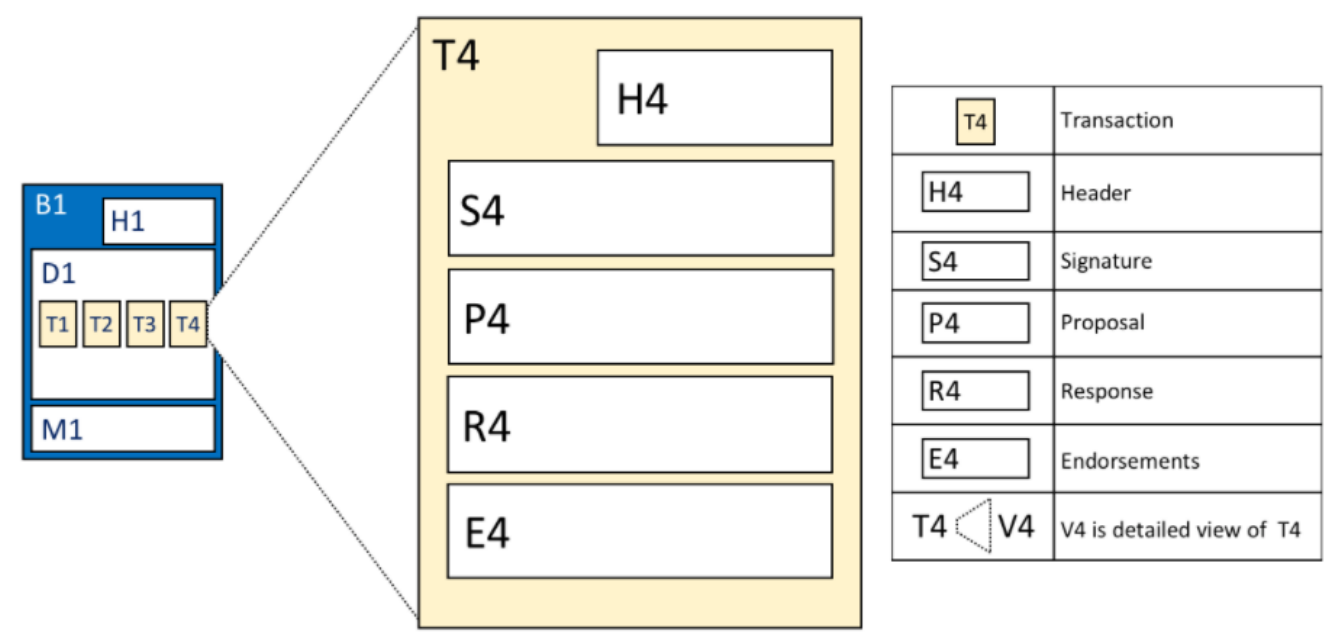

Figura 3 - Detalhes típicos do registro de uma transação (Fonte: Hyperledger, 2020a)

A transação T4, da figura acima, contém os seguintes registros:

- Header (H4): Contém informações gerais sobre a transação

- Assinatura (S4): Assinatura criptográfica da transação, utilizada para a checagem da veracidade da transação.

- Proposta (P4): A transação em si, são escritos na forma de parâmetros de entrada que serão tratados e que vão alterar o estado atual do registro na blockchain.

- Resposta (R4): A resposta para a transação, registra o estado anterior e o novo estado do objeto da transação.

- Endosso (E4): Assinaturas de validação da transação, podem ser exigências contratuais, pré-requisitos ou aprovações de membros pertencentes à organização.

De maneira resumida, uma blockchain é estruturada como uma sequência de blocos de transações conectados por criptografia. Cada bloco contém um conjunto de transações que alteram ou atualizam os estados dos objetos registrados na blockchain. 


\subsection{1 \\ 0 mecanismo de consenso}

Tanto a validação da cadeia de blocos existente na rede quanto a inserção de um novo bloco de transações devem ser aprovadas pela própria rede, através de um mecanismo de consenso. O mecanismo de consenso é um dos atributos que garante a segurança e a imutabilidade das informações registradas na blockchain.

Dentre diversos mecanismos existentes, pode-se citar o PoW (Proof of Work) e o PoS (Proof of Stake) como sendo os mais comumente utilizados (Atlam; Wills, 2019). A principal diferença entre os mecanismos de consenso está na maneira como a blockchain delega e recompensa o trabalho de validação das transações realizadas.

Proof of Work é o mecanismo adotado nas blockchains Bitcoin e Litecoin. O participante necessita provar que certo trabalho computacional foi dispendido para que seja qualificado para a inclusão de novos blocos de transação à blockchain. Este mecanismo é considerado de baixa complexidade de verificação, entretanto, exige um enorme gasto energético e computacional (Kamilaris; Fonts; Prenafeta-Boldú, 2019). O trabalho computacional dos participantes é recompensado através da distribuição de uma criptomoeda, Bitcoin, por exemplo.

Proof of Stake é um mecanismo aonde os participantes da rede são selecionados de forma aleatória para a validação da nova transação. A probabilidade de seleção de um membro é proporcional à quantidade de criptomoedas que este detém (Bentov; Gabizon; Mizrahi, 2016). Este mecanismo possui um gasto energético significativamente menor do que o PoW, uma vez que os validadores são selecionados de forma aleatória, e não através do gasto computacional. A recompensa aos nós participantes acontece na forma de uma tarifa sobre a transação realizada, podendo esta ser paga através de um criptoativo.

\section{2}

\section{DLT: Distributed Ledger Technology}

Uma blockchain é um tipo de DLT - distributed ledger technology, ou uma 
tecnologia de livro-razão distribuído, em livre tradução para o português. Este livro-razão registra todo o histórico de transações já realizadas na blockchain e é considerado distribuído pelo fato de estar armazenado em múltiplos computadores ao mesmo tempo. O principal objetivo de uma DLT é garantir que toda a rede valide o conteúdo do livro-razão e certifique de forma consensual a inserção de novos blocos de transações.

\section{3 \\ Principais Características de uma Blockchain}

As principais características de uma blockchain são: descentralização, imutabilidade, transparência, eficiência e segurança (Atlam; Wills, 2019):

\subsection{1 \\ Descentralização}

A arquitetura de livro-razão descentralizada se apoia em todos os participantes da rede para a sustentação e manutenção da blockchain. Isso permite uma maior agilidade no processamento e elimina diversas fragilidades de uma solução centralizada, como a dificuldade de escalabilidade e uma eventual falha generalizada causada por um problema no sistema central.

\subsection{2 Imutabilidade}

Uma das características principais de uma blockchain está na capacidade de garantir a integridade dos dados através de registros imutáveis. Diferentemente de um sistema centralizado aonde a base de dados fica sob domínio de uma única entidade e que a garantia de integridade depende da confiança em uma terceira parte, a característica distribuída de uma blockchain não permite que uma alteração no histórico de transações seja realizada sem o consenso de toda a rede participante. Enquanto existirem participantes suportando a continuidade da blockchain, todos os registros da cadeia de blocos continuarão salvos e seguros de adulterações. 


\subsection{3 \\ Transparência}

Todas as transações realizadas na blockchain estão permanentemente disponíveis para consulta das partes envolvidas. Isso traz uma maior confiança e segurança para a realização das transações entre as partes.

\subsection{4 \\ Eficiência}

A característica descentralizada da blockchain faz com que ela seja mais eficiente do ponto de vista de custo, velocidade de transação e gestão de risco se comparada a uma solução centralizada tradicional. Como os dados de transações estão distribuídos por toda a rede, e não em um banco de dados central, torna-se mais fácil e transparente a verificação de todas as informações.

\subsection{5 \\ Segurança}

A arquitetura de dados e o funcionamento da blockchain fazem com que ações maliciosas e alteração de dados sejam praticamente impossíveis de se realizar. A adulteração de uma informação por um dos participantes da blockchain exigiria que este tivesse mais do que $51 \%$ do poder de processamento de toda a rede que a sustenta, isso torna matematicamente impossível a alteração de algum registro. Os participantes depositam no mecanismo de consenso da blockchain a confiança sobre a integridade dos dados de transação.

\section{4}

\section{A Evolução das Blockchains}

Conforme proposto por Swan (2015), a evolução da tecnologia de blockchain desde sua criação em 2008 até os dias atuais pode ser quebrada em 3 fases de uma revolução tecnológica: Blockchain 1.0, 2.0 e 3.0. Cada fase representando uma etapa da evolução da tecnologia e um novo horizonte de sua aplicação nos mais diversos contextos.

Segundo Swan (2015) e outros autores como Davidson; De Filippi; Potts (2016), Schmidt; Wagner (2019) e Tapscott; Tapscott (2016), a blockchain é uma tecnologia tanto transformacional quanto revolucionária, e sua aplicação tem o 
poder de criar novas formas organizacionais e institucionais de governança econômica.

Todas as esferas da organização social, econômica, política e legal podem se beneficiar do uso de tal tecnologia, o que deixa em evidência o seu potencial disruptivo.

\subsection{1}

\section{Blockchain 1.0: Moeda}

Corresponde à criação do Bitcoin, a primeira proposta de aplicação de uma blockchain, para solucionar um problema de gastos dobrados em compras digitais. A origem da tecnologia, como proposto por Nakamoto (2008), teve como objetivo trazer maior segurança para as transações financeiras digitais. Através do uso de um selo digital, a transação financeira seria registrada de forma permanente na blockchain do Bitcoin o que evitaria um duplo gasto com o mesmo recurso financeiro. Os pilares da tecnologia são a criptografia de dados e a distribuição do poder de processamento.

Dentro desta blockchain, todas as transações são únicas, públicas e verificáveis por qualquer membro a ela pertencente. A tecnologia permitiu, portanto, a descentralização do sistema financeiro. A partir dela, não há mais a necessidade de uma terceira parte central responsável pela intermediação financeira entre duas pessoas/instituições, uma vez que todas as transações são públicas e inalteráveis.

\subsection{2}

\section{Blockchain 2.0: Contratos}

Desde a concepção do Bitcoin, Nakamoto já havia idealizado uma aplicação da blockchain para além das transações financeiras. O protocolo da blockchain do Bitcoin foi concebido de forma a permitir a programação de outras moedas e de contratos digitais. Em um comunicado de 2010, Nakamoto reforçou que a estrutura da blockchain suportaria diversos outros tipos de transação, como contratos autoexecutáveis, de arbitragem, multipartidários e outros.

Nesta etapa do desenvolvimento, que ainda é corrente, a versatilidade de uso da blockchain permitiu o surgimento de smart contracts, smart properties e outras formas de soluções descentralizadas e autônomas.

A blockchain, portanto, deixa de ser um instrumento para transação monetária e passa a ser um instrumento para o registro de qualquer tipo de 
transação e ativos. Os smart contracts, por exemplo, são contratos digitais de execução automática segundo critérios programáveis, já as smart properties são registros de propriedade e transferência de ativos físicos através da blockchain.

Esta etapa foi marcada, principalmente, pelo projeto Ethereum ${ }^{1}$, uma blockchain programável que permite a criação de aplicações descentralizadas. A blockchain é sustentada por usuários que são remunerados através do criptoativo Ether $(\mathrm{ETH})$.

Se durante a Blockchain 1.0 houve a descentralização do sistema financeiro, a Blockchain 2.0 permitiu a descentralização do mercado de forma mais genérica, onde qualquer ativo pode ser transacionado de forma descentralizada e autônoma.

\subsection{3 \\ Blockchain 3.0: Além de Moedas e Contratos}

Muito além das soluções para transações financeiras e execução de smart contracts e smart properties, a tecnologia da blockchain tem o potencial de reconfigurar outras indústrias e até mesmo a organização social. De maneira simplificada, a blockchain é um novo paradigma de organização que permite menores atritos, maior eficiência nas interações e suporta uma escala e escopo globais (Swan, 2015). Este potencial possibilita tanto uma alocação mais eficiente e automatizada de recursos em uma indústria, por exemplo, quanto uma maior coordenação e colaboração social.

Alguns exemplos do uso da blockchain integrada a processos empresariais ou industriais podem ser encontrados na literatura: Atlam; Wills (2019), Pahl; El loini; Helmer, (2018) e Schatsky; Muraskin (2015) propuseram a integração da blockchain com a Internet das coisas (IOT) para o controle de processos industriais; Dogo Et Al. (2019) propuseram o uso da blockchain integrada à inteligência artificial para a gestão de distribuição de água; Hirbli (2018), Kamilaris; Fonts; Prenafeta-Boldú (2019), Kshetri (2018) e Tian (2016, 2017) estudaram amplamente a aplicação da blockchain na cadeia de suprimentos de alimentos, commodities e até produtos acabados.

Do ponto de vista social, Tapscott; Tapscott (2016) estudam diversos aspectos da organização humana e a possibilidade de uso da blockchain. Alguns exemplos estão na inclusão social e financeira através de micro pagamentos e microfinanciamento, na restruturação de processos democráticos como serviços

\footnotetext{
${ }^{1}$ https://ethereum.org/en/
} 
governamentais, eleições, política e justiça, na distribuição de direitos autorais e até na colaboração coletiva.

Trata-se de uma tecnologia relativamente recente e de enorme potencial, muitas das aplicações ainda estão em desenvolvimento e, muito provavelmente, acompanharemos sua evolução e difusão de forma bastante intensa nos próximos anos.

\section{5}

\section{Os tipos de Blockchain}

Existem três tipos de blockchain: pública, privada ou em consórcio. As principais características de cada uma delas estão resumidas na Tabela 1. Os três tipos se diferem, principalmente, no tipo de acesso e no tipo de controle exercido sobre os nós participantes.

\begin{tabular}{|c|c|c|c|}
\hline & \multicolumn{3}{|c|}{ Tipo de Blockchain } \\
\hline & Pública & Privada & Consórcio \\
\hline Acesso & Público & Público ou Restrito & Público ou Restrito \\
\hline Consumo de Energia & Alto & Baixo & Baixo \\
\hline Velocidade de transação & Mais alta & Mais baixa & Mais alta \\
\hline Eficiência & Alta & Baixa & Alta \\
\hline Segurança & $\begin{array}{l}\text { Prova de Trabalho (PoW), } \\
\text { Prova de Participação (PoS) e } \\
\text { outros }\end{array}$ & $\begin{array}{l}\text { Participantes pré-aprovados } \\
\text { para participação e consenso } \\
\text { por votação, multipartido }\end{array}$ & $\begin{array}{l}\text { Participantes pré-aprovados } \\
\text { para participação e consenso } \\
\text { por votação, multipartido }\end{array}$ \\
\hline Imutabilidade & $\begin{array}{l}\text { Praticamente impossível de } \\
\text { alterar os dados }\end{array}$ & $\begin{array}{l}\text { Possibilidade de alteração dos } \\
\text { dados }\end{array}$ & $\begin{array}{l}\text { Possibilidade de alteração dos } \\
\text { dados }\end{array}$ \\
\hline Transparência & $\begin{array}{l}\text { Informação disponível para } \\
\text { todos os nós }\end{array}$ & $\begin{array}{l}\text { Informação restrita às partes } \\
\text { envolvidas, controle sobre } \\
\text { privacidade de dados }\end{array}$ & $\begin{array}{l}\text { Informação restrita às partes } \\
\text { envolvidas, controle sobre } \\
\text { privacidade de dados }\end{array}$ \\
\hline Processo de Consenso & $\begin{array}{l}\text { Sem restrição de acesso e } \\
\text { anônimo }\end{array}$ & $\begin{array}{l}\text { Permissão para acesso e nós } \\
\text { conhecidos }\end{array}$ & $\begin{array}{l}\text { Permissão para acesso e nós } \\
\text { conhecidos }\end{array}$ \\
\hline Determinação de Consenso & Todos os nós mineradores & Organização central & $\begin{array}{l}\text { Nó líder determinado para } \\
\text { cada tipo de transação }\end{array}$ \\
\hline Rede & Totalmente descentralizada & Centralizada & Semi-centralizada \\
\hline Tipo de ativo & $\begin{array}{l}\text { Ativo específico por } \\
\text { blockchain }\end{array}$ & Qualquer ativo & Qualquer ativo \\
\hline Tempo de aprovação & Ordem de minutos & Ordem de milisegundos & Ordem de milisegundos \\
\hline
\end{tabular}

Tabela 1 - Tipos de Blockchain (Behnke; Janssen, 2020; Lu Et Al., 2019; Pahl; El loini; Helmer, 2018) 


\subsection{1 Blockchain pública}

Uma blockchain pública, como a do Bitcoin, não possui limitações de acesso. Qualquer pessoa pode se conectar, ter acesso aos dados de transações nela registrados e participar dos mecanismos de consenso. Este tipo de blockchain é o modelo de completa descentralização.

De maneira geral, as transações são registradas em alta velocidade, todos os nós podem participar dos mecanismos de consenso e a segurança de dados é bastante elevada, sendo praticamente impossível alterá-los.

\subsection{2 \\ Blockchain privada}

Uma blockchain privada se refere a uma blockchain cujo direito de edição ou registro está limitado a uma organização ou grupo de indivíduos. $O$ direito de visualização de dados de transações também é controlado e pode, eventualmente, ser aberto para o exterior, ou ser limitado aos participantes da blockchain. Todos os atributos de segurança e a determinação de consenso sobre as transações está sob domínio da organização central controladora da blockchain. Esta solução pode ser adotada dentro de uma organização ou empresa, onde o escopo ficará restrito ao contexto corporativo. Neste tipo de blockchain, o problema de confiança nas outras partes não fica totalmente resolvido, como em uma blockchain pública, mas todas as transações ficam registradas de forma permanente, o que facilita processos de auditoria.

\subsection{3 \\ Blockchain em consórcio}

Uma blockchain em consócio tem um escopo mais amplo do que uma blockchain privada, os participantes são membros de um consórcio e não necessariamente pertencem a uma mesma empresa. Os direitos de edição e leitura de dados são definidos pelas regras do consórcio, e os participantes terão acesso aos dados que the sejam pertinentes, apenas. Os mecanismos de consenso são definidos pelo consórcio para cada tipo de transação.

Uma blockchain em consórcio combina atributos das blockchains privadas e públicas. 


\section{6 \\ As Blockchains Privadas}

Conforme introduzido no capítulo anterior, uma blockchain privada é uma solução restrita a um conjunto de indivíduos ou organização central, aonde os direitos de edição e acesso às informações são controlados. Uma blockchain privada é um tipo conhecido como permissioned blockchain.

As permissioned blockchains operam dentro de um contexto de participantes conhecidos e controlados, aonde certas regras de governança são pré-determinadas, de forma a se garantir um nível de confiança operacional. Estas blockchains promovem um meio para que um grupo de indivíduos que possuem um interesse comum possam realizar transações, mesmo que não confiem totalmente uns nos outros (Hyperledger, 2018).

Neste contexto, as identidades de todos os participantes são conhecidas e qualquer tentativa de adulteração de informações na blockchain deverá passar pelas regras de governança e aprovação pré-estabelecidas. Além disso, qualquer inserção incorreta de dados será facilmente rastreável pelos demais participantes envolvidos ou pela organização central responsável pela blockchain.

Esta solução tem boa aderência para empresas que pretendam usufruir dos benefícios de uma blockchain sem renunciar à privacidade de dados e controle sobre os membros participantes.

\section{7}

\section{Os Smart Contracts}

De maneira simplificada, um smart contract é um contrato cuja execução seja automatizada (Savelyev, 2017), ou um algoritmo computacional de transação que tem a capacidade de executar os termos de um contrato entre as partes (Szabo, 1997). Como as condições contratuais são programáveis, a execução dos termos do contrato fica condicionada automaticamente ao cumprimento de todas as cláusulas. Os riscos contratuais e as chances de oportunismo em um smart contract são praticamente inexistentes.

Os smart contracts em uma blockchain representam as regras do negócio de maneira codificada. Os objetos de transação podem ser representados por smart contracts e a blockchain tem a capacidade de performar um papel de 
governança sobre as cláusulas contratuais. Cada etapa de execução será registrada e aprovada através dos mecanismos de consenso da blockchain e o status de cada smart contract será propagado para toda a rede e para os demais membros de forma sequencial. No contexto de uma blockchain, diversos smart contracts podem ser executados ao mesmo tempo, de forma paralela e com diferentes nós participantes.

\section{8 \\ O HyperLedger}

O Hyperledger é uma plataforma criada em 2015 por um grupo de empresas interessadas na tecnologia da blockchain. Essas empresas decidiram unir esforços para estudar, desenvolver e promover a tecnologia da blockchain para uso empresarial (Hyperledger, 2018). A plataforma é um guarda-chuva de projetos e sub-plataformas modulares e open-source que ficam sob a tutela do The Linux Foundation e que contam com a colaboração de mais de 230 empresas, dentre elas IBM, SAP, Intel e Airbus.

A proposta do projeto é tornar a tecnologia acessível para as empresas, de forma a promover a adoção da blockchain no meio corporativo. O Hyperledger agrega um vasto grupo de ferramentas, bibliotecas, blockchains e domínios que se adequam às necessidades das empresas (Villacreses Ponce, 2020).

A Figura 4 apresenta um resumo do framework do projeto Hyperledger com as suas diferentes blockchains, bibliotecas e ferramentas.

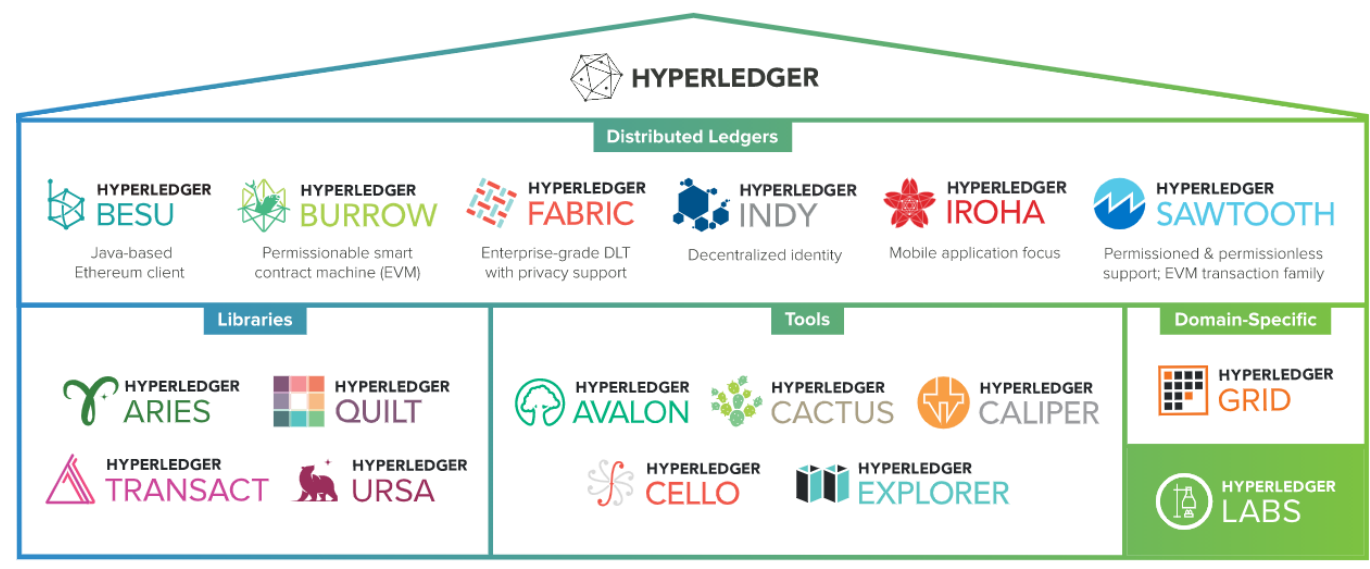

Figura 4 - Tecnologias presentes no guarda-chuva do projeto Hyperledger (Fonte: Hyperledger, 2020b) 
A intenção do desenvolvimento de uma plataforma colaborativa e opensource é facilitar a adoção e integração da tecnologia aos sistemas proprietários das organizações. O projeto, em 2018, já contava com mais 28.000 participantes e com 10 grupos de trabalho ativos (Hyperledger, 2018).

\section{9 \\ Referencial Teórico}

Como apresentado por Davidson; De Filippi; Potts (2016), a blockchain é uma nova tecnologia institucional que possibilita novos tipos de contratos e organizações, ou seja, estruturas e instituições alternativas de governança. Ela elimina, ou inibe, o comportamento oportunista através de uma transparência radical das transações associada aos mecanismos de criptografia e consenso coletivo, e da execução dos smart contracts. Ou seja, ela possibilita o estabelecimento de um novo tipo de coordenação socioeconômica entre as empresas.

Chen $(2016,2018)$ complementa que a Blockchain, através da democratização de acesso às informações e da significativa redução dos custos de transação, estabelece um mecanismo de confiança nas contrapartes envolvidas. Não por menos, a revista The Economist em matéria de 2015 chama a Blockchain de The Trust Machine, uma tecnologia que permite com que indivíduos que não necessariamente confiam um no outro possam colaborar sem precisar de uma autoridade central mediadora.

Outros autores, como Catalini; S.Gans (2019) e Schatsky; Muraskin (2015), reforçam que a blockchain permite um registro de transações de forma distribuída, de autenticação descentralizada, de forma criptografada, segura, barata e verificável por todos os pertencentes à rede, desta forma reduzindo significativamente os custos de transação.

Mais recentemente, Ahluwalia; Mahto; Guerrero (2020) argumentam que a blockchain consegue auxiliar em todos os aspectos que influenciam os custos de transação, desde a redução de oportunismos e ineficiências na tomada de decisão através da democratização das informações, execução de smart contracts verificáveis e auto executados; passando pela redução das incertezas ambientais através da velocidade de elaboração dos contratos, simplificação das estruturas 
de governança e dispensa de terceira parte acreditada; e chegando finalmente na redução de incertezas nos investimentos em ativos específicos, através da tokenização destes ativos na cadeia de suprimentos.

Finda a contextualização sobre a tecnologia da blockchain e da utilização de smart contracts, no próximo capítulo será apresentado o setor de óleo e gás, mais especificamente a distribuição de combustíveis. Este setor será escolhido para o desenvolvimento de uma solução baseada em blockchain para a melhoria de governança na cadeia de distribuição de produtos. 


\section{3 \\ O Mercado de Distribuição de Combustível}

\section{1}

\section{Do Poço ao Posto: Um Panorama Geral}

A cadeia de distribuição de petróleo engloba todas as atividades contidas entre a exploração do petróleo bruto na natureza até a distribuição ao consumidor final, fazendo parte desta indústria a exploração, o desenvolvimento, a produção, o refino, o processamento, o transporte, a importação e a exportação de petróleos, gás natural, hidrocarbonetos e seus derivados (Soares; Leal; Azevedo, 2003).

A Figura 5 apresenta um esquema resumido da cadeia de distribuição de petróleo e derivados e seus fluxos logísticos. A cadeia se inicia no poço de exploração de petróleo cru, quando as empresas de exploração extraem o petróleo das jazidas localizadas em terra ou no subsolo marinho.

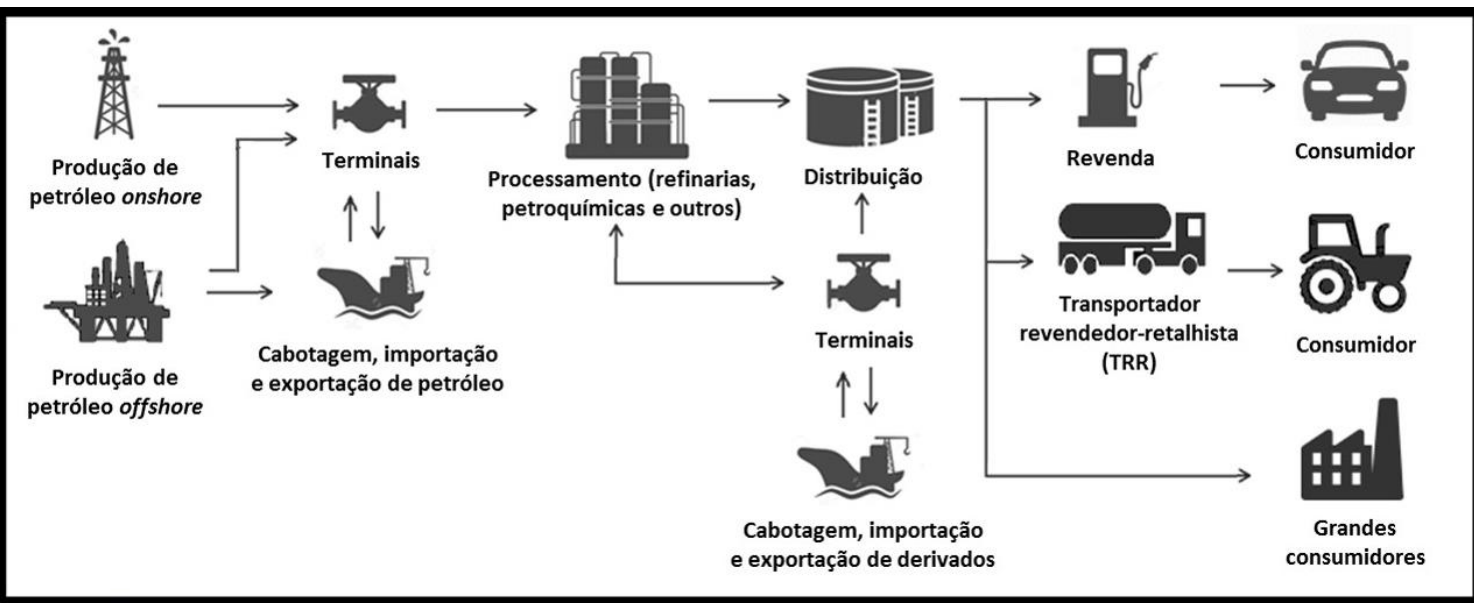

Figura 5 - Cadeia de abastecimento (Fonte: Empresa De Pesquisa Energética - EPE, 2018)

O óleo cru extraído dos poços é transportado via oleodutos e/ou navios até os terminais de armazenamento de óleo bruto, onde o petróleo é estocado até o envio às refinarias ou até sua comercialização. Os terminais de armazenamento de petróleo cru servem como hub de estocagem, e atuam como ponto de recebimento e envio de petróleo para as refinarias, para outros terminais ou para consumidores de matéria bruta. Os terminais contam com conexão aos sistemas logísticos de petróleo, como oleodutos e portos de embarque de navios-tanque. 
Dos terminais de armazenamento, o petróleo cru é enviado às refinarias onde ele será processado para a produção de derivados diversos, dentre eles a gasolina e o óleo diesel.

Após o refino, a gasolina e o óleo diesel acabados poderão ser enviados diretamente às distribuidoras ou a outros terminais de armazenamento que posteriormente realizarão o envio às distribuidoras. Para o recebimento de produto diretamente das refinarias, algumas distribuidoras constroem bases de distribuição conectadas a esta via oleodutos. Estas bases são conhecidas como bases primárias. As bases que são abastecidas por terminais ou por outras bases de distribuição são conhecidas como bases secundárias.

O recebimento de produto das refinarias em sua base distribuição marca o início da cadeia de suprimento de derivados da distribuidora.

\section{2 \\ Upstream, midstream e downstream}

A indústria do petróleo pode ser dividida em três principais grupos de atividades da cadeia de valor: Upstream, Midstream e Downstream.

O Upstream refere-se às etapas de desenvolvimento, estudo, exploração e produção de petróleo e gás natural. O Midstream refere-se a qualquer etapa intermediária de transporte e armazenamento de óleo bruto e gás natural, antes da etapa de refino. Fazem parte do Midstream os sistemas logísticos de oleodutos, navios, sistemas ferroviários e rodoviários responsáveis pelo transporte de óleo não processado. O Downstream, finalmente, refere-se à ponta da cadeia de produção, contendo as etapas de refino, distribuição e comercialização dos derivados de petróleo e gás natural. Fazem parte do Downstream os sistemas logísticos responsáveis pela movimentação de produtos acabados de refino, como gasolina, diesel, querosene, nafta e outros.

A Figura 6 ilustra a cadeia de valor completa do setor de óleo e gás: 


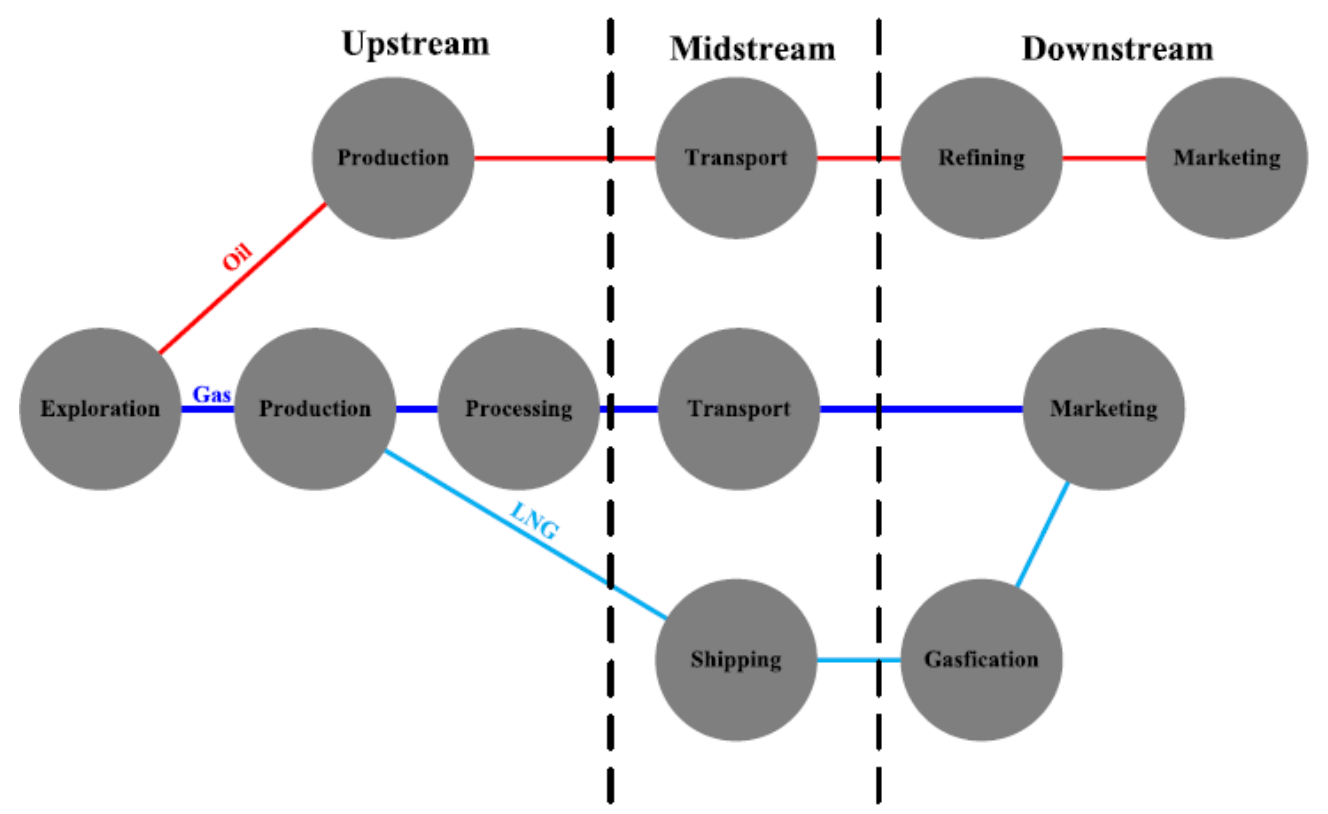

Figura 6 - Cadeia de valor do setor de óleo e gás (Fonte: Lu et al., 2019)

Atualmente, a partir da portaria ANP №116/2000 (Agência Nacional Do Petróleo - ANP, 2000), a legislação brasileira proíbe a integração vertical do setor de óleo e gás, determinando a separação das atividades de Upstream/Midstream das atividades de Downstream. As empresas que realizem a exploração e refino, portanto, são proibidas de revender combustíveis diretamente aos postos de combustíveis, deixando esta função para as distribuidoras, que atuam como intermediárias entre o refino e o consumidor final.

\section{3 Da Distribuidora ao Cliente Final}

A distribuição de combustíveis faz parte da cadeia de downstream da indústria do petróleo, e engloba as etapas de suprimento, armazenamento, mistura e distribuição de combustíveis derivados de petróleo, sendo eles, principalmente, etanol, gasolina, diesel e combustível de aviação. Uma empresa que atue na distribuição de combustíveis é conhecida como uma distribuidora.

Além de derivados de petróleo, como diesel e gasolina, a distribuidora também recebe e armazena biocombustíveis (etanóis e biodiesel), que poderão ser vendidos diretamente, no caso do etanol hidratado, ou que deverão ser misturados aos derivados para a comercialização aos consumidores finais, no caso do etanol anidro e biodiesel. No Brasil, o governo estipula a obrigatoriedade 
de mistura de biocombustíveis aos derivados de petróleo para a comercialização aos consumidores finais. Para a gasolina, desde 1993 através da Lei no 8.723, de 28 de outubro, ficou obrigatória a utilização de percentual mínimo de mistura de etanol anidro na composição da gasolina comum e aditivada. Para o diesel, desde 2004 através da resolução №42 da ANP, de 24 de novembro, ficou definido percentual mínimo de biodiesel no diesel. Atualmente, as definições sobre as políticas de adoção e incentivo ao uso de biocombustíveis no Brasil estão sob responsabilidade do programa RenovaBio, estabelecido pelo governo pela Lei $\mathrm{n}^{0}$ 13.576, de 23 de dezembro de 2017..

A infraestrutura operacional de uma distribuidora contempla essencialmente bases de distribuição onde os combustíveis são recebidos, armazenados, misturados e distribuídos para os seus clientes, que podem ser outras distribuidoras, grandes empresas ou o consumidor final, pessoa física, através de postos de combustíveis.

A mesma portaria nำ116/2000 da ANP, que proibiu a verticalização no setor de óleo e gás, também estabeleceu a relação entre as distribuidoras e os postos revendedores. Os postos que adotem a marca da distribuidora deverão manter contratos de exclusividade de fornecimento de combustíveis com essas distribuidoras. Estes postos são chamados de postos embandeirados. Por sua vez, os postos que optarem por não adotar a bandeira de nenhuma distribuidora, conhecidos como bandeira branca, estão dispensados de contratos de exclusividade de fornecimento. Além disso, a legislação que as distribuidoras não podem deter e operar postos de combustíveis diretamente, devendo contar com uma rede de postos que sejam os intermediários entre elas e o consumidor final.

O papel da distribuidora, portanto, se resume em adquirir os produtos derivados e biocombustíveis puros, realizar as misturas em suas bases e revender o produto final para os postos de combustíveis. A Figura 7 apresenta um esquema simplificado do fluxo operacional de distribuição.

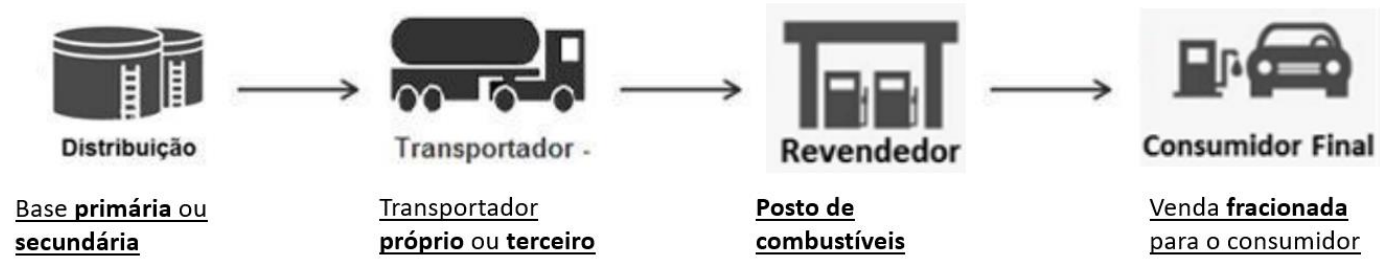

Figura 7 - Esquema simplificado do fluxo operacional de distribuição (Fonte: Elaboração própria e Empresa De Pesquisa Energética - EPE, 2018) 
A distribuidora, através de suas bases, recebe e armazena os combustíveis. A distribuição até os postos de combustíveis é realizada através de transportadores, que podem ser próprios ou terceiros. Os revendedores, ou operadores dos postos, que são os clientes diretos das distribuidoras, recebem os produtos e fazem a revenda para o consumidor final.

\section{4}

\section{Fragilidades na Cadeia de Distribuição}

A cadeia de Óleo e Gás, desde a exploração até a venda final, tem uma característica de rede onde os esforços de cooperação e investimentos são compartilhados entre os seus diversos participantes. Isso faz com que a confiança nas terceiras-partes seja necessária durante o processo de transação, e que existam brechas para conflitos de interesses, fraudes e ineficiências, ou seja, incertezas durante as transações. Essas incertezas estão associadas a eventos não previsíveis e não probabilísticos que podem interferir nos negócios entre os postos e as distribuidoras. Elas surgem do comportamento oportunista por parte dos envolvidos na cadeia e as distribuidoras se veem obrigadas a empregar mecanismos de governança através de contratos, vistorias, coleta de amostra testemunha e outras, na tentativa de aumentar a coordenação entre os atores e reduzir tais oportunismos. Neste contexto, o controle das transações e validações das informações exigem esforços de seus participantes, além de aumentar significativamente o tempo e o custo das transações (Soares; Saes, 2015).

No setor de distribuição, as principais incertezas relatadas na cadeia estão no controle de qualidade, na fidelização do cliente, na preservação da imagem e da marca, no atendimento às normas, na metrologia e no controle documental. A incerteza mais relevante, entretanto, está na qualidade do produto, mais especificamente na preocupação com a adulteração de combustíveis (Soares; Saes, 2015). A adulteração consiste "na mistura de qualquer substância diferente ou acima das especificações permitidas, originando um produto de qualidade inferior", tal prática, em desconformidade com as especificações da ANP, ocorre de tal forma que "a quantidade real de produto vendido pode ser menor do que a demonstrada na bomba, ou nas demais etapas da cadeia de distribuição" (Gonçalves; Guerra, 2012).

Além dos esforços das distribuidoras, o setor conta com a fiscalização e 
controle de outros órgãos, como o Inmetro, as prefeituras, os órgãos de meio ambiente e a própria ANP, agência reguladora instituída em 1997 com o objetivo de promover a regulação, contratação e fiscalização das atividades econômicas integrantes da indústria do petróleo no país.

Conforme descrito por Gonçalves e Guerra (2012), as atribuições da ANP convergem com os interesses dos agentes econômicos integrantes da cadeia de distribuição de combustíveis, pois os poderes de fiscalização e regulação permitem à agência atestar a qualidade dos produtos sendo comercializados, coibindo eventuais infrações. A ANP, através do Programa de Monitoramento da Qualidade de Combustíveis, instituído em 1999, por exemplo, visa acompanhar a qualidade do produto comercializado no País.

A adulteração de combustível, além de atentar contra os direitos do consumidor e aumentar as incertezas quanto à qualidade e segurança dos produtos e operações, atinge negativamente a arrecadação tributária e os resultados das companhias.

Apesar de todos os esforços empenhados pelas distribuidoras, pela sociedade e pelos órgãos governamentais, a adulteração de combustíveis ainda é uma realidade da sociedade brasileira. Por este motivo, no próximo capítulo, pretende-se propor a utilização da tecnologia da Blockchain para a redução das incertezas na cadeia de distribuição de combustíveis, reduzindo significativamente os oportunismos dos agentes participantes. 


\section{4 Novo Modelo de Negócio de Distribuição de Combustíveis em Blockchain}

Neste capítulo, será proposto um novo modelo de negócio para o rastreamento da cadeia de distribuição de combustíveis, baseado na tecnologia da Blockchain. Este modelo permitirá o acompanhamento e registro das etapas de venda e distribuição de combustíveis, desde a origem no distribuidor, até o consumidor final, trazendo maior transparência e segurança para toda a cadeia.

A proposta traz a criação de um sistema de DLT que funcionará em sincronia com o sistema de ERP (Sistema Integrado de Gestão Empresarial) existente em uma distribuidora e que manterá o registro das informações essenciais do produto ao longo da cadeia. Ao final da cadeia, no ato da venda ao consumidor no posto de combustíveis, todas as informações de origem e a certificação do volume vendido estarão disponíveis para consulta, e um mecanismos de incentivo será adotado para que estas informações sejam verificadas e exigidas pelo consumidor.

A origem da transação será 0 ato da venda do combustível ao revendedor, aonde o volume vendido de determinado combustível será registrado na Blockchain pela distribuidora através de um smart contract. A partir daí, todas as etapas da transação serão encadeadas ao contrato de origem, trazendo um histórico operacional, de movimentações e de informações de qualidade relacionadas ao volume do produto vendido. Este volume registrado na Blockchain será um par digital do volume físico vendido e as informações a ele relacionadas estarão registradas na Blockchain, de forma imutável e verificável aos envolvidos na cadeia.

O objetivo deste modelo é permitir que todos os envolvidos na cadeia não tenham dúvidas quanto à qualidade e origem do produto. Além de reduzir os custos envolvidos nos diversos mecanismos de coordenação das transações, o modelo reduz drasticamente a possibilidade de oportunismos ao longo da cadeia, sejam por parte dos transportadores, sejam por parte dos revendedores.

A distribuidora se beneficiará do modelo com a redução dos seus custos administrativos, maior transparência na distribuição e contará com um controle 
adicional na ponta da cadeia que é o engajamento do cliente no controle de qualidade e de adulterações. O transportador também se beneficiará com a redução dos custos administrativos, além de ter um maior controle sobre a atuação de seus motoristas. O revendedor terá o benefício da certificação de sua atuação e da qualidade e origem do produto que está vendendo, isso traz um benefício direto para sua imagem e na fidelização dos seus clientes. Finalmente, o consumidor terá a certeza sobre a origem e qualidade do produto que está adquirindo, além de se beneficiar de um incentivo financeiro para adesão ao processo de certificação do produto.

Para a operacionalização deste sistema, faz-se necessário definir as principais característica da Blockchain, o modelo que será adotado, os diferentes atores (nós) participantes e seus papéis e permissões ao longo da cadeia, além dos pontos críticos que envolvem a validação de volumes vendidos para a execução dos smart contracts e a transferência das informações físicas para a Blockchain.

\section{1 \\ Escolha da Blockchain}

Um dos passos mais importantes na definição de um sistema com a tecnologia Blockchain é a escolha do modelo mais adequado para a aplicação desejada. A Figura 8 traz um fluxograma de tomada de decisão que foi traduzido livremente e adaptado do trabalho proposto por Lu Et Al. (2019), baseado no white paper da CAICT (2018).

Através de respostas consecutivas a perguntas sobre o possível cenário de aplicação de uma Blockchain, pode-se concluir a aplicabilidade ou não desta tecnologia e, se aplicável, qual o tipo mais adequado. Propõe-se percorrer o fluxograma a partir do cenário proposto neste presente trabalho:

\section{Cenário de aplicação}

Rastreamento e controle do fluxo de venda de combustível desde a base de distribuição até o consumidor final através de smart contracts e digitalização de ativos físicos. 


\section{Necessidade de um banco de dados?}

Sim, pretende-se registrar e tornar disponível para consultas futuras e auditorias todo o processo de venda e transporte do combustível pela cadeia de distribuição. As informações serão disponibilizadas para a distribuidora, para a transportadora, para o revendedor e para o consumidor final.

\section{Necessidade de diversos editores de dados?}

Sim, ao longo da cadeia, conforme o produto vendido for avançando em direção ao consumidor final, as etapas de transporte e transferência serão acrescentadas ao contrato de venda inicial. Essas informações serão atualizadas pela transportadora e pelo revendedor, e precisarão ser validadas pela distribuidora. Portanto, além da distribuidora, os intermediários terão direito à edição de certos dados.

\section{Os editores de dados são conhecidos?}

Sim, tanto o transportador quanto o revendedor são conhecidos pela distribuidora, e eles precisarão ser cadastrados e aprovados por ela antes de participarem da cadeia de distribuição e da blockchain.

\section{Os interesses podem ser conflituosos?}

Sim, tanto o transportador quanto o revendedor podem ter interesse na manipulação de informações e do próprio produto em benefício próprio e em detrimento da distribuidora. São amplamente reportados casos de desvio e roubo de produto, manipulação dos instrumentos de medição de volume e adulteração de produto e da qualidade.

\section{Há disposição para se confiar numa terceira parte?}

Não, o interesse desta aplicação está na transparência e rastreabilidade integral dos dados e do processo de venda do produto, desta forma dispensando a necessidade de confiança em terceiras partes e reduzindo significativamente os custos extras de coordenação e governança contratuais. 


\section{Necessidade de controle sobre o sistema?}

Sim, o sistema será gerenciado e controlado pela distribuidora. Ela ainda será responsável pela liberação de acessos e cadastramento dos participantes da cadeia de distribuição.

\section{Escopo do consenso}

O escopo do consenso das transações está contido dentro da distribuidora proprietária do sistema, ou seja, dentro de uma organização.

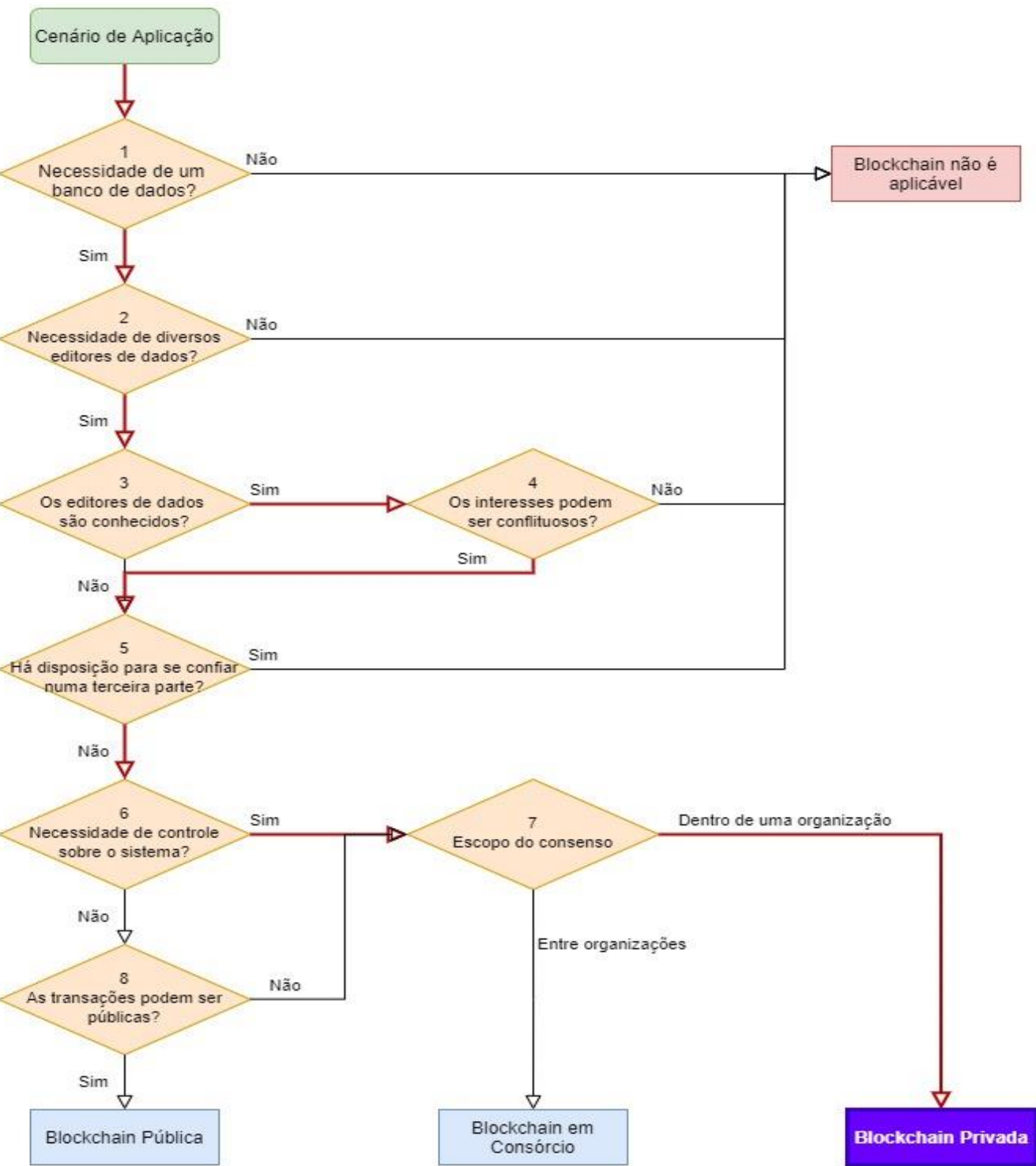

Figura 8 - Fluxograma para escolha do tipo de blockchain segundo aplicação Fonte: elaboração própria, CAICT (2018) e Lu et al. (2019) 
Após percorrer o fluxograma, pode-se concluir que a Blockchain mais adequada para a aplicação proposta é uma Blockchain Privada, que será controlada pela própria distribuidora, a principal interessada na redução dos desvios existentes na cadeia de distribuição.

\subsection{1 \\ O HyperLedger Fabric}

Neste modelo de negócio proposto, a plataforma escolhida para o desenvolvimento do sistema foi o HyperLedger Fabric. Conforme apresentado no capítulo 2.8, o HyperLedger é um ecossistema colaborativo lançado pela Linux Foundation em 2015 para desenvolvimento de soluções em blockchain para aplicação corporativa. O HyperLedger Fabric é uma das plataformas que compõe o ecossistema e que permite o desenvolvimento de soluções com arquitetura modular, escalável e com o nível de privacidade e segurança controlados pelas empresas participantes. É um framework que permite a criação de uma Blockchain Privada para uso empresarial.

HyperLedger Fabric é uma plataforma de ledger (livro-caixa) que permite a criação e gerenciamento de smart contracts e a gestão das transações entre os membros participantes. Por ser uma rede privada e de acesso restrito, todos os nós participantes são conhecidos e necessitam de aprovação do administrador da rede para o ingresso e interação nas transações. Tanto os acessos às informações quanto as permissões de edição e visualização das transações são controladas pelo administrador. Este conjunto de características permite com que regras de governança contratuais sejam implementadas na rede, o que garante uma relação de confiança e transparência entre os diversos membros envolvidos (Villacreses Ponce, 2020).

Esta tecnologia consegue, portanto, resolver o problema presenciado nas blockchains públicas que é o acesso irrestrito às informações por todos os membros participantes da rede. Como cada membro tem acesso apenas às transações e contratos que sejam pertinentes ao seu contexto, a rede consegue garantir os benefícios da transparência e confiabilidade entre os membros envolvidos, enquanto assegura a confidencialidade das informações. Ou seja, as empresas podem ter acesso aos benefícios de uma blockchain pública num contexto privado. 
Da mesma forma que uma blockchain pública, o HyperLedger Fabric também trabalha com mecanismos de consenso no registro das transações, e cada membro participante possui uma cópia local atualizada da cadeia de blocos das transações e participa da validação das novas transações segundo regras específicas de governança de rede (Hyperledger, 2020a). O tipo de mecanismo de consenso pode ser configurado segundo a necessidade da rede e a vantagem de se conhecer todos os membros participantes é que mecanismos de Proof-ofWork, mais custosos do ponto de vista de processamento e mais lentos no registro dos blocos, podem ser dispensados.

Finalmente, sua arquitetura modular e personalizável permite a aplicação nos mais diversos contextos corporativos para otimização de processos, melhoria na governança contratual e, como neste presente trabalho, gestão da cadeia de suprimentos.

\section{2 \\ Membros participantes e permissões}

Os participantes da cadeia de distribuição de combustíveis são a própria distribuidora, o transportador, o revendedor e o consumidor final. A seguir, serão detalhados seus papéis e responsabilidades no processo.

\subsection{1 \\ A distribuidora}

A distribuidora é a maior interessada e beneficiada pelo modelo de negócio proposto, portanto, ela seria a responsável pela implementação da Blockchain Privada e pela administração de acessos, permissões e configuração das regras de governança de rede e dos smart contracts. Alguns dos seus papéis seriam:

- Criação e configuração da Blockchain Privada;

- Criação e configuração dos contratos "modelo" para comercialização de combustível;

- Criação das funções que poderão ser chamadas pelos membros participantes 
- Criação dos tipos de transações que serão criadas e agregadas à blockchain ao longo da cadeia de distribuição

- Cadastro e homologação dos membros participantes

- Aprovações/atuação em casos excepcionais de disputas de informações, por exemplo: validação de volume de combustível recebido pela revenda (conforme detalhado no capítulo 4.4)

- Administradora da rede da blockchain privada e nó validador

No contexto deste trabalho, serão consideradas como padrão para discussão o nível de infraestrutura tecnológica e logística existente nas grandes distribuidoras do país, que representam juntas parcela significativa do mercado. Isso significa considerar que a distribuidora dispõe de um sistema informatizado para controle de pedidos de combustível e acompanhamento do processo de distribuição.

\subsection{2 \\ O transportador}

O transportador tem papel de mover o produto vendido da base de distribuição até o revendedor. Como muitas das fraudes documentadas na cadeia de distribuição estão na etapa de transporte, onde o produto está sob posse do motorista, sua permissão será basicamente de visualização das informações pertinentes ao transporte que será realizado e de inclusão/validação de informações cadastrais sobre o motorista, caminhão e carga. Um dos objetivos do modelo de negócio proposto é a redução significativa das brechas para comportamento oportunístico na etapa de transporte do produto vendido. Por este motivo, os transportadores não terão permissões explícitas para visualização ou alteração de informações contratuais entre a distribuidora e o revendedor.

Quando nos referimos ao transportador, consideramos tanto a empresa transportadora como uma entidade agregadora de motoristas sob diversos contratos de trabalho, quanto o próprio motorista que realizará o transporte do produto. Na situação mais completa de uma empresa contatada para o transporte que destaca um motorista para a realização do serviço, tanto a empresa quanto o funcionário participarão da cadeia com responsabilidades e permissões distintas, sendo as principais: 


\section{A empresa}

A empresa teria como permissão a visualização dos contratos de transporte a ela destinados e teria como papéis durante a prestação de serviços:

- Manutenção das informações cadastrais pertinentes à operação, como por exemplo: documentos necessários para o funcionamento da empresa.

- Solicitação e manutenção de cadastro de motoristas à distribuidora

- Aceitação e execução dos contratos de transporte enviados pela distribuidora

- Indicação de motoristas para o atendimento ao cronograma de entregas

\section{O motorista}

O motorista também teria como permissão a visualização dos contratos de transporte a ele destinados e teria como papéis:

- Validação do recebimento da carga a ser transportada

- Manutenção das informações cadastrais pertinentes à operação, como por exemplo: certificados de conformidade do caminhão-tanque, documentos pessoais, exames médicos

- Atualização de informações de entrega da carga ao revendedor

\subsubsection{O revendedor}

O revendedor é o operador do posto de combustíveis, podendo ser proprietário ou um comodatário de um posto de terceiros. Em desvios reportados na cadeia de distribuição, ele pode ser noticiado como vítima de oportunismos por parte dos transportadores, ou como protagonista de desvios como adulteração de combustíveis e equipamentos, operação irregular, desvios de qualidade, entre outros. Por estes motivos, o modelo de negócio proposto tem como objetivo trazer mais segurança para o revendedor no recebimento do produto dos transportadores, mas também garantir um controle maior das distribuidoras sobre eventuais desvios de conduta dos revendedores. 
O revendedor teria como permissão a visualização dos contratos pertinentes às suas ordens de compra e seus papéis seriam:

- Solicitação dos pedidos de combustível via sistema, o pedido dará início a um smart contract que seria rastreado ao longo de toda a cadeia

- Manutenção das informações cadastrais pertinentes à operação, como por exemplo: licenças operacionais, dados sobre inspeções periódicas, entre outros

- Visualização e acompanhamento dos pedidos realizados

- Validação do volume recebido e coleta de amostra testemunha para atestação de qualidade. Esta etapa é uma das mais importantes na cadeia de distribuição, aonde o volume recebido é medido e confrontado com o volume enviado pela distribuidora. Esta etapa será detalhada adiante, no capítulo 4.4 .

\subsection{4 0 consumidor final}

O consumidor do combustível no posto é o ponto final da cadeia de distribuição e o elo mais fraco de toda a cadeia. Ele está sujeito aos oportunismos praticados ao longo da cadeia, geralmente tem pouco acesso às informações de qualidade do combustível que está comprando e, necessariamente, precisa confiar no revendedor e na distribuidora que fornece o combustível adquirido. Hoje, a cadeia não supre o consumidor de informações suficientes para tranquilizá-lo quanto à origem e qualidade do produto que está sendo comprado. Apesar dos esforços das distribuidoras e dos órgãos reguladores, a relação de compra se resume a uma confiança do consumidor na bandeira e no posto em questão.

O modelo de negócio proposto neste trabalho visa dar mais transparência sobre a origem do produto adquirido, além de prover um maior poder de fiscalização para o consumidor final. Sua permissão seria de visualização das informações da cadeia de distribuição sobre os produtos adquiridos e seu papel seria de verificação das informações acerca do produto adquirido. Para o desempenho deste papel de "regulador" sobre o combustível adquirido, está sendo proposto um sistema de incentivo, que será apresentado no capítulo 4.6. 


\section{3 Fluxo operacional}

O fluxo operacional que será coberto se inicia no pedido de compra de combustíveis enviado pelo revendedor à distribuidora e se encerra com a venda de combustível ao consumidor final, no posto de combustíveis. Este fluxo representa um esquema de distribuição típico para este setor, e possui características e processos semelhantes entre a maioria das distribuidoras em operação no país. Estas distribuidoras, geralmente, operacionalizam este fluxo de maneira digital em sistemas de ERP próprios e centralizados, com baixa integração e transparência com os diversos atores envolvidos. Estes sistemas de ERP são responsáveis por registrar as ordens de compra e venda, os fluxos logísticos e operacionais, os controles de estoque e os controles de qualidade. Estas informações, entretanto, ficam limitadas ao escopo da distribuidora.

O diferencial do modelo proposto está no registro das etapas do fluxo operacional em uma Blockchain privada através de smart contracts e na disponibilização de informações pertinentes para cada ator envolvido no processo de distribuição. Desta forma, pode-se trazer maior transparência à cadeia, maior segurança para as contrapartes envolvidas e menores custos transacionais (Schmidt; Wagner, 2019).

O fluxograma da Figura 9, em sua porção superior denominada "Processo de venda de combustível", representa o passo a passo da cadeia de distribuição com as atividades desempenhadas por cada um dos atores, desde o pedido de compra até a conclusão da transação no posto. A porção inferior, denominada "Blockchain" representa as atividades que serão registradas na Blockchain privada paralelamente ao fluxo físico já operacional nas distribuidoras. Nas seções seguintes, o fluxograma do processo de venda será dividido em quatro blocos de processos e cada bloco será detalhado separadamente. 

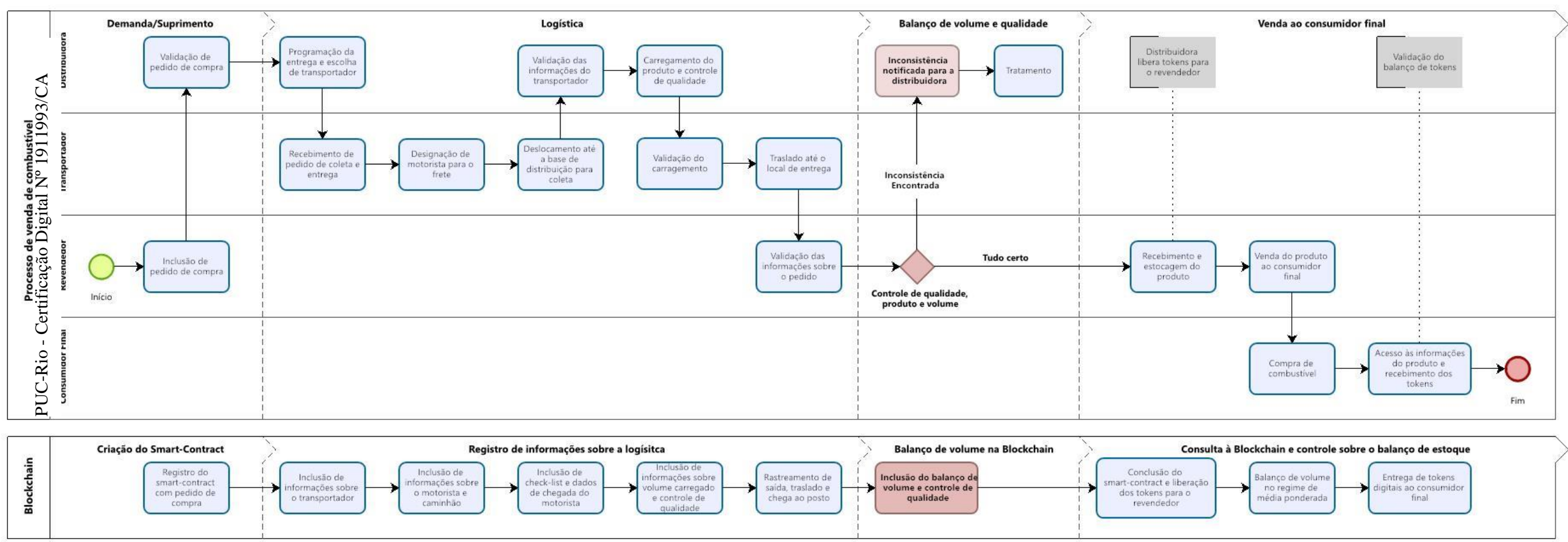

Figura 9 - Fluxograma completa do processo de venda de combustível da distribuidora até o consumidor final. (Fonte: Elaboração própria)

Elabora com a ferramenta Bizagi Modeler versão 3.8.0.179 


\subsection{1 Bloco 1 - Demanda/Suprimento}

O processo de venda de combustível se inicia na ponta da demanda, quando o revendedor solicita à distribuidora um volume de determinado combustível. Este revendedor pode ter um contrato de fornecimento e exclusividade com a distribuidora, se ele for um cliente "embandeirado", ou não, se ele for um posto "bandeira branca".

No caso de clientes embandeirados, os termos do contrato de fornecimento, como preço e prazos para pagamento e entrega, já estão préestabelecidos. O revendedor, portanto, apenas formaliza o volume do produto a ser adquirido e ratifica o prazo para a entrega a cada pedido periódico.

No caso de clientes bandeira branca, os termos para fornecimento não estão formalizados em contrato, portanto sofrem alterações conforme variações do mercado e, normalmente, são acordados em cada negociação. Neste caso, o revendedor pode realizar cotação de fornecimento com mais de uma distribuidora e optar por enviar o pedido para a que melhor atender à sua necessidade no momento da compra. As informações de volume, preço e prazo de entrega são acordadas em cada negociação.

Em ambos os casos, os pedidos são aprovados e registrados no sistema de ERP da distribuidora e dão início a um workflow interno de fornecimento.

\section{Na blockchain}

A validação do pedido de compra por parte da distribuidora culminará na criação de um smart contract com os termos do fornecimento. Informações como cliente, produto, volume, preço, prazo de entrega, responsáveis envolvidos pela negociação e pedido, e as condições gerais de fornecimento poderão ser registradas, bem como os gatilhos para as futuras execuções automáticas de pagamento ou abertura de exceções para apuração da distribuidora.

Hoje em dia, as distribuidoras já possuem sistemas com portais específicos para registro e acompanhamento de pedidos de entrega, o registro na blockchain privada seria uma evolução destes sistemas, com a migração de um servidor central local para o HyperLedger Fabric. 


\subsection{2 Bloco 2 - Logística}

$\mathrm{Na}$ sequência do workflow de fornecimento, assim que o pedido de compra de combustível é validado, ele entra na programação de entrega da distribuidora, aonde uma equipe de inteligência logística, em coordenação com a base de distribuição, define a melhor rota, cronograma, caminhão e transportador para a entrega prevista. A escolha do transportador, muitas vezes, é precedida por contratos logísticos de longo prazo, aonde as condições gerais de transporte e preços por rotas já são pré-estabelecidas, tornando a alocação de rotas muito mais eficiente.

O transportador selecionado para a entrega, então, recebe o pedido de coleta e entrega, confirma a sua disponibilidade para o serviço e designa o motorista/caminhão que será responsável pela coleta na base de distribuição. No dia programado para a entrega, o motorista designado se apresenta na base de distribuição para a coleta do combustível e, antes de realizar o carregamento, tem todos os dados conferidos pela distribuidora. Nesta etapa de validação de informações do transportador, os dados do motorista são checados, documentos de conformidade do caminhão são conferidos e um checklist geral do caminhão é realizado pela distribuidora, o serviço de entrega só poderá acontecer se nenhuma informação estiver incompleta ou se nenhum documento do motorista/caminhão estiver faltando. Por se tratar de uma entrega de produto perigoso e de um setor altamente regulado, nenhuma inconsistência de segurança ou legal pode existir na cadeia de suprimentos.

Sendo concluídas todas as etapas de checagem prévia e segurança, a distribuidora realiza o carregamento do caminhão-tanque com o produto $e$ volume que serão entregues em determinado posto de combustíveis. Nesta etapa, também são realizadas conferências de volume e controle de qualidade através da coleta de amostras testemunha. Tais amostras são armazenadas e testadas periodicamente pelas distribuidoras, e também são enviadas para os postos de combustíveis para armazenamento dos revendedores. No caso de algum desvio de qualidade, estas amostras são utilizadas na investigação da origem do problema. Como conclusão da etapa de carregamento, o motorista em conjunto com a distribuidora, valida o volume e produto carregado no caminhão-tanque e lacra o compartimento em questão. Este lacre é a garantia de que 0 produto não deveria sofrer adulteração até 0 recebimento pelo 
revendedor no posto, momento em que o lacre é violado.

$\mathrm{Na}$ sequência do carregamento, o motorista coleta as Notas Fiscais de venda e de transporte e realiza o transporte até o posto de combustíveis, dando sequência ao próximo Bloco de Balanço de Volume e Qualidade.

\section{$\underline{\text { Na blockchain }}$}

Todas as etapas percorridas neste processo, desde a seleção do transportador até a emissão das notas fiscais deverão ser registradas na blockchain, sendo elas:

- Seleção do transportador: Todas as informações referentes ao transportador e sua relação com a distribuidora, sejam elas cadastrais ou contratuais, estarão registradas na blockchain. Estas informações seriam conferidas e incluídas na evolução do smart contract, no momento da designação do transportador para o pedido de coleta de combustível. Os transportadores, bem com os motoristas, estariam registrados na blockchain como membros participantes.

- Designação do motorista: No momento da designação do motorista pelo transportador para o serviço de entrega, todas as informações pertinentes ao mesmo e ao caminhão serão incluídas no smart contract de fornecimento. No caso de qualquer inconsistência ou pendência cadastral, a associação à blockchain já denunciaria previamente e a continuidade do processo só poderia acontecer na regularização de tais pendências, ou na designação de outro motorista/caminhão com dados regularizados.

- Checklist de chegada à base: No acolhimento do motorista e do caminhão para a coleta na base de distribuição, as informações cadastrais pertinente serão levantadas novamente e conferidas com as apresentadas pelo motorista. Além disso, o checklist realizado será registrado na blockchain e garantirá que para aquela coleta específica, todas as informações requeridas de segurança e legais estavam sendo cumpridas.

- Volume carregado e controle de qualidade: $\mathrm{Na}$ conclusão do carregamento, todas as informações referentes ao produto e volume carregado, bem como as informações de qualidade, amostra testemunha, lacres e notas fiscais serão registradas na blockchain para garantir o atendimento completo aos requisitos legais e para 
salvaguardar a correta execução do procedimento operacional.

- Rastreamento do transporte: Todas as informações referentes ao transporte podem ser rastreadas por tecnologia embarcada nos caminhões, compartilhada via GPS em tempo real e podem ser incluídas na blockchain. Desta maneira, quaisquer desvios de rota ou paradas inesperadas, ou alteração dos parâmetros dos produtos poderão ser rastreadas, conforme proposto por Ajao et al. (2019).

As informações registradas nesta etapa servem para garantir a execução completa e correta do procedimento operacional, bem como o atendimento às legislações vigentes. Estas informações servirão para garantir os volumes e a qualidade do produto entregue pelo distribuidor ao transportador. Estes dados poderão servir para posteriores consultas e para a resolução de eventuais disputas entre a distribuidora, o transportador e/ou o revendedor que receberá o produto. Tendo as etapas de conferência registradas de forma imutável na blockchain e sendo elas disponíveis para consulta dos envolvidos, diminui-se significativamente o espaço para oportunismos na cadeia, tornando-se mais evidente a origem do desvio ao longo da cadeia (Ahluwalia; Mahto; Guerrero, 2020).

\subsection{3 \\ Bloco 3 - Balanço de volume e qualidade}

Entre a chegada do motorista com o produto ao posto de combustíveis e a efetiva entrega dele existe uma nova etapa de controle de qualidade, produto e volume a ser realizada pelo responsável do posto de combustíveis, geralmente um gerente operacional, com acompanhamento do motorista responsável pelo transporte. Antes do descarregamento do produto no tanque do posto, os lacres são conferidos e violados, o volume no caminhão-tanque é verificado visualmente, novas amostras são coletadas e testadas para validação da qualidade do produto e, após o descarregamento, o volume entregue é medido no tanque, para conferência com o declarado na nota fiscal de venda e acordado no ato da compra. Quaisquer divergências de qualidade e volume são, neste momento, relatadas à distribuidora e darão início a tratativas próprias de reparação, podendo ser desde um acerto do volume vendido até a devolução completa da carga à base de 
distribuição. Geralmente, um certo nível de variação de volume entre o carregado e o medido na entrega é aceitável, tendo em vista as propriedades físico-químicas dos produtos. A variação do volume por conta da temperatura e perdas decorrentes de evaporação, normalmente, são aceitáveis e esperadas até certo nível. Desvios de qualidade aferidos na entrega, entretanto, não são tolerados, e a carga pode ser devolvida caso as propriedades não atendam à legislação vigente.

Após esta etapa de conferência, não sendo identificados desvios de qualidade e volume, o processo de entrega é considerado concluído. Esta etapa pode ser considerada uma das mais críticas no processo de entrega porque é onde podem ser identificados desvios realizados na etapa de transporte.

\section{$\underline{\text { Na blockchain }}$}

Do ponto de vista da blockchain, esta etapa é um milestone de validação de todas as informações fornecidas até o momento, e que garantirá o correto balanço de volume do produto vendido pela distribuidora. Até então, todas as informações registradas na blockchain tiveram origem na distribuidora e foram apenas ratificadas pelo transportador. A distribuidora registrou as informações contábeis sobre o volume vendido e sobre a qualidade dos produtos, no ato do recebimento do produto no posto, estas informações devem ser conferidas e reafirmadas pelo transportador e pelo revendedor para garantir o fechamento contábil e fiscal correto da distribuidora. Nesta conferência de entrega, ainda existe algum espaço para ajuste do volume recebido e, estando dentro da margem de variação esperada no transporte, o volume aferido no recebimento será registrado como o volume efetivamente vendido pela distribuidora ao posto.

$\mathrm{Na}$ blockchain, este volume recebido será validado automaticamente e dará uma conclusão ao smart contract de venda, se estiver dentro da margem esperada na distribuição. Se o volume e/ou qualidade não estiverem de acordo com o esperado, isso será registrado como uma não conformidade e tratativas individuais deverão ser conduzidas pela distribuidora.

Neste momento de aferição de volume final e de conclusão do smart contract de venda, propõe-se a emissão de tokens de incentivo para o revendedor na quantidade equivalente ao volume vendido. Estes tokens seriam os equivalentes digitais ao volume recebido pelo revendedor e seriam utilizados para distribuição ao consumidor final, numa proposta de recompensa pela participação na conferência da qualidade e origem do produto vendido. Este processo será 
detalhado no capítulo 4.6. Como a plataforma do HyperLedger Fabric não possui um sistema de recompensa na forma de criptoativos como blockchains públicas, propõe-se a adoção dos próprios sistemas de recompensa e fidelidade existentes nas distribuidoras, como por exemplo o KM de Vantagens da distribuidora Ipiranga, o Premmia da BR Distribuidora e o ShellBox da distribuidora Raizen, que atua sob a bandeira de Shell no Brasil. O revendedor receberia o equivalente ao volume comprado em pontos de fidelidade desses programas, em uma taxa de conversão qualquer escolhida pela distribuidora, e poderia distribuir a mesma quantidade recebida de forma fracionada ao consumidor final. Desta forma, o balanço de pontos de fidelidade seria um equivalente contábil do volume comprado, não podendo divergir do volume físico em estoque.

\subsection{4}

\section{Bloco 4 - Venda ao consumidor final}

Depois de concluída a entrega física do produto e a distribuição dos tokens de incentivo para o revendedor, inicia-se o processo de venda ao consumidor final. O consumidor, através do uso das ferramentas e aplicativos existentes nas distribuidoras, poderá consultar a origem do produto vendido, as informações de qualidade aferidas durante o processo e demais informações que as distribuidoras queiram compartilhar com os clientes no ato da venda. Além disso, os consumidores receberão a quantidade de tokens equivalente ao volume adquirido.

Este sistema permitirá que as distribuidoras tenham, em tempo real, acesso ao balanço de tokens de cada revendedor, podendo conferir qualquer desvio no volume físico ou digital.

\section{Na blockchain}

Sob a perspectiva da blockchain, este processo de venda ao consumidor final desencadeará uma transferência de tokens ao consumidor, momento em que um ajuste no balanço será registrado para atualização de estoque. Esta transferência poderá ser realizada através de um novo smart contract que trará as informações do contrato original de venda ao revendedor. Ele trará em si o histórico de transações desde a origem do produto na distribuidora até o 
recebimento e balanço final de volume e qualidade no posto de combustíveis. Este smart contract também registrará a movimentação dos tokens (pontos de fidelidade) da distribuidora ao revendedor, e do revendedor ao consumidor final. O sistema de balanço será organizado na forma de média ponderada, desta forma os volumes sendo comercializados poderão estar misturados fisicamente e a distribuição dos tokens poderá representar a proporcionalidade dos volumes físicos sendo distribuídos.

\section{4 \\ O recebimento do produto - o ponto sensível}

A eficácia da solução proposta depende da qualidade das informações que serão inseridas na blockchain, se alguma informação incorreta for inserida, ela será registrada de forma permanente e será propagada para as demais etapas do processo de distribuição. Por este motivo, a gestão da rede, usuários e permissões, e controle de edição e inclusão de informações são geridos pela distribuidora. Qualquer intenção de inclusão de novas informações ou alteração de dados por parte dos usuários deverá passar, de alguma maneira, pela aprovação da distribuidora.

Durante a maior parte do processo de distribuição, as informações são geridas e incluídas na blockchain pela distribuidora. Como os processos ocorrem majoritariamente dentro da base de distribuição, as informações estão sob controle direto da distribuidora, ela valida os documentos apresentados, as amostras de produto, os parâmetros de processo e todas as demais informações que serão registradas na blockchain, desde a chegada do motorista até a sua partida. No entanto, do momento em que o motorista deixa a base de distribuição até o recebimento do produto no posto de combustíveis, a distribuidora deixa de ter o controle direto sobre o produto. Evidentemente que alguns mecanismos foram criados para reduzir as chances de oportunismo durante o transporte, como o rastreamento em tempo real do caminhão e a implantação de sensores para medição de parâmetros do produto nos caminhões. Mesmo assim, a distribuidora seguirá sem informações direta sobre o produto até 0 momento do descarregamento no posto.

Neste momento, o revendedor fará novos testes de qualidade e validará o volume recebido sem a presença da distribuidora. Qualquer inconsistência de volume ou qualidade será notificada à distribuidora e ela decidirá como será o 
tratamento da divergência. Geralmente, um certo nível de variação de volume é aceitável, por conta da variação da temperatura do produto e, consequentemente, de sua densidade.

Esta etapa de recebimento é considerada um ponto sensível do processo porque ela define o efetivo volume físico recebido pelo revendedor e que será usado para o controle contábil, fiscal e financeiro, tanto do posto quanto da distribuidora. Uma divergência de apuração de qualidade e volume, seja ela intencional ou não, trará consequências para a distribuidora e para o revendedor, podendo ocasionar perdas financeiras, perdas legais e até maiores riscos na segurança operacional e ambiental.

Com a implantação da blockchain, este balanço de volume continuará sendo, de certa maneira, um ponto sensível porque, além das implicações operacionais, ele será responsável pelo balanço do volume dos ativos digitais e pela correta distribuição dos tokens de incentivo. Qualquer informação incorreta registrada na blockchain ocasionará uma quebra dos controles contábeis e inconsistências entre os volumes entregues e vendidos. A implantação de um sistema paralelo em uma blockchain, entretanto, possui a vantagem de inibir o comportamento oportunista, uma vez que as informações contratuais estarão acessíveis para a cadeia e que quaisquer desvios serão facilmente rastreáveis até sua origem.

Apesar desta vulnerabilidade, a implantação de uma blockchain e a disponibilização das informações de processo para os nós participantes ajudará a inibir comportamentos oportunísticos (Schmidt; Wagner, 2019), dificultando a adulteração e desvios de combustíveis. Além disso, a blockchain tem grande sinergia com a tecnologia conhecida como Internet das Coisas (IoT) e pode abrir caminho para a aceleração da digitalização da cadeia de suprimentos, com a implantação de novos controles e sensores ao longo do processo (Galvez; Mejuto; Simal-Gandara, 2018).

\section{5}

\section{O balanço de tokens}

Com a conclusão do descarregamento no posto de combustíveis e com os volumes validados pela distribuidora, o posto receberá os tokens de incentivo em volume equivalente ao combustível adquirido. Estes tokens serão distribuídos 
em uma plataforma própria de programa de incentivo, já existente na maioria das grandes distribuidoras do país. Esta plataforma fará a gestão dos tokens recebidos pelo posto e distribuirá os mesmos aos consumidores finais, ao final de cada abastecimento. As plataformas existentes nas distribuidoras poderão passar a operar dentro da blockchain privada, desta forma, todas as transações poderão ser registradas na rede de forma permanente e acessível aos nós pertinentes.

O balanço de tokens servirá como um livro contábil do combustível vendido da distribuidora ao posto e do posto aos consumidores finais. Tendo todas as transações sido registradas na blockchain, a distribuidora terá um balanço exato e em tempo real dos fluxos de entrada e saída dos postos, e qualquer divergência neste batimento de volumes poderá ser investigado e tratado de forma quase instantânea.

Adicionalmente, para contemplar a mistura de combustíveis de diferentes lotes, como ocorre naturalmente no processo de distribuição, o sistema deverá realizar um controle de balanço de tokens de forma proporcional aos volumes e lotes recebidos. Ou seja, em cada descarregamento, o sistema realizará uma conta de proporcionalidade de lotes de combustível recebidos no mesmo tanque e realizará a distribuição dos tokens de segundo esta proporcionalidade. Desta maneira, tanto o consumidor final quanto a distribuidora poderão ter acesso à informação completa sobre o combustível que está sendo vendido, incluindo a quais lotes de entrega o volume pertence. A particularidade da cadeia de distribuição de combustíveis impossibilita o controle de estoque através de métodos como PEPS (FIFO), UPES (LIFO) ou custo médio ponderado, como utilizado amplamente em outras cadeias de distribuição, porque existe a mistura de diferentes lotes durante o processo. A maneira de absorver esta particularidade nos controles desta cadeia é através de balanços de massa e/ou volumes.

\section{6 \\ Transparência e incentivo - gerando engajamento}

Além do benefício direto da distribuição de tokens sobre o controle de compra e venda de combustíveis, tem-se o benefício indireto da recompensa do consumidor final pela participação no processo de compra e verificação das informações sobre o produto vendido.

Como apresentado por Hirbli (2018), a implantação de uma blockchain 
em uma cadeia de distribuição conta com o desafio da separação entre o mundo físico e o digital, e uma solução bem-sucedida deve se apoiar tanto no pilar da tecnologia como no pilar do fator humano. Por maior que seja o grau de digitalização da cadeia física, inevitavelmente, algum nível de envolvimento humano será necessário para o bom funcionamento e precisão das informações contidas no sistema. Os envolvidos devem estar engajados e precisam encontrar valor na solução para que se possa garantir o bom funcionamento da blockchain na cadeia de distribuição. A maneira de promover tal engajamento está na escolha correta do conjunto de incentivos que serão dados aos participantes.

A distribuidora, o transportador e o revendedor possuem os incentivos já enumerados da transparência de informações e da redução dos custos operacionais. O consumidor final, entretanto, poderá não enxergar diretamente o benefício da transparência de informações sobre o produto que está comprando. Neste caso, propõe-se a distribuição de tokens digitais como um incentivo a mais para a sua participação na cadeia. Estes tokens deverão poder ser convertidos em vantagens para o consumidor, na forma de descontos nos combustíveis ou troca por benefícios, e deverão ser distribuídos em quantidade proporcional ao volume adquirido, fechando assim o balanço contábil de tokens do posto.

Com este sistema de incentivo, pretende-se potencializar o engajamento e a fidelização do consumidor final, tornando-os membros ativos da cadeia. A distribuição dos tokens deverá estar atrelada à conferência das informações registradas na blockchain sobre a origem e a qualidade do produto. Desta forma, os consumidores serão engajados à fiscalização dos postos de combustíveis. Se um consumidor se deparar com alguma inconsistência ou ausência de informação, ou não receber o volume de tokens esperado, um alerta será enviado para a distribuidora que poderá agir imediatamente na investigação da divergência.

\section{7 \\ Por que este modelo é mais eficiente?}

O grande diferencial existente na adoção de uma solução em blockchain para a cadeia de suprimentos reside no poder de se estabelecer novas estruturas de governança sobre as transações e contratos, possibilitando assim a redução dos custos de transação.

Nas principais distribuidoras do país, o modelo atual de gestão da cadeia 
conta com sistemas digitais tradicionais, nem sempre integrados entre os diversos blocos do processo e com muitas etapas ainda não digitalizadas. A integridade e completude das informações depende fortemente de fatores humanos e eventuais divergências podem passar desapercebidas. Além disso, muitas das etapas, como: validação de documentação, conferências de conformidades legais e de segurança e testes de qualidade em amostras podem acontecer exclusivamente no meio físico, não sendo registradas em qualquer sistema digital.

A proposta de digitalização da cadeia de distribuição de combustíveis com o uso de uma blockchain privada é mais eficiente do que o modelo atual porque garante a integridade das informações de todo o processo, proporciona maior transparência para a cadeia e tem a capacidade de reduzir os custos administrativos e os oportunismos da cadeia:

\section{Integridade das informações}

A proposta de integração de toda a cadeia de distribuição garante que não existam quebras de informação entre as diversas etapas do processo. A adoção deste sistema único que cubra desde a origem do contrato de compra até a entrega final do produto fará com que a pegada digital do produto seja construída ao longo da cadeia e que qualquer discordância de informação seja identificada em tempo real. Adicionalmente, o fato deste sistema ser construído em uma blockchain garantirá todos os benefícios desta tecnologia, dentre eles: a imutabilidade dos registros de transação, a validação de forma autônoma e descentralizada das informações, e a segurança e rastreabilidade dos dados.

Nenhum dos nós da cadeia será capaz de alterar qualquer dado de transação ou vencer qualquer etapa do processo sem que as condições mínimas sejam garantidas.

\section{$\underline{\text { Transparência para a cadeia }}$}

O modelo propõe a participação ativa de todos os membros pertencentes à cadeia de distribuição. Todas as informações pertinentes aos membros, sejam elas cadastrais ou transacionais, estarão disponíveis para consulta dentro da blockchain. Esta transparência e disponibilidade das informações sobre as transações é um dos benefícios da adoção de uma blockchain.

Do ponto de vista dos transportadores, da distribuidora e dos revendedores, a transparência das informações reduzirá as disputas entre estes 
e elevará o nível de confiança geral das relações. As assimetrias de informações serão reduzidas significativamente.

Do ponto de vista do consumidor final, o acesso às informações sobre a origem e qualidade do produto proporcionará uma maior confiança no posto e na distribuidora, e promoverá uma maior fidelização à marca.

\section{Redução dos custos administrativos}

A adoção dos smart contracts para as transações de venda de combustível permitirá a padronização dos contratos de venda e exigirá o cumprimento das cláusulas contratuais para sua execução. Além disso, tal execução se dará de forma automática dentro da blockchain, com as condições contratuais e milestones programáveis. Isso significa que o acompanhamento do contrato será realizado dentro da blockchain de forma automática, em paralelo à evolução da cadeia de suprimentos.

Esta tecnologia também trará maior agilidade para a elaboração e execução de contratos e reduzirá de maneira significativa as disputas sobre cláusulas contratuais, uma vez que as condições estarão acordadas e registradas de forma permanente na blockchain. Além disso, o modelo proposto reduzirá de forma significativa os custos sobre a governança contratual das empresas.

Uma maior agilidade na elaboração de contratos e uma menor necessidade de governança sobre os contratos existentes significam um menor custo administrativo total.

\section{Redução de oportunismos na cadeia}

A combinação dos benefícios citados anteriormente e a possibilidade de controle contábil sobre a movimentação de produto (e de tokens) ao longo de cadeia permitirá uma redução significativa na vulnerabilidade da cadeia para oportunismos. Eventuais desvios serão facilmente identificados e rastreados até sua origem, e os oportunistas poderão ser culpabilizados. 


\section{5 \\ Conclusão}

A tecnologia da Blockchain por muitos é considerada uma nova disrupção tecnológica, capaz de ajudar a moldar a nova ordem econômica e social com suas mais diversas possiblidades de aplicação. Baseando-se em um conceito bastante simples, a tecnologia se mostra extremamente versátil e torna clara as mais diversas possiblidades de aplicação para a solução de questões que dependem de uma maior segurança nas transações. As mais diversas atividades do nosso dia a dia podem se beneficiar da tecnologia da Blockchain, seja para a melhoria da segurança no pagamento digital, como foi o propósito original se sua criação, seja no registro de propriedades, ou no rastreamento da cadeia de produção, no financiamento coletivo, no micro pagamento, no registro de propriedade intelectual e diversas outras aplicações encontradas na literatura ou já implementadas.

No presente trabalho, pretendeu-se apresentar uma das soluções possíveis para a melhoria da cadeia de distribuição de combustíveis. Com a adoção de uma solução baseada em blockchain, pode-se melhorar a governança sobre as relações comerciais entre os diversos participantes da cadeia de distribuição. Esta solução propõe maior transparência e segurança quanto à integridade dos dados de transações, tornando praticamente impossível a adulteração de informações e os oportunismos na cadeia.

Além da melhoria das transações, a solução também possibilita um maior controle sobre os volumes distribuídos e efetivamente vendidos, se valendo da propriedade de livro-caixa digital da Blockchain para uma validação em tempo real sobre os volumes transacionados.

A solução também incentiva a participação ativa dos consumidores finais sobre a verificação da origem e qualidade do produto comprado. Através de um sistema de recompensa, pretende-se engajar os consumidores a atuarem como fiscais das distribuidoras nos postos de combustíveis. Este sistema, além de trazer maior conhecimento sobre o produto vendido para os consumidores, ajuda no controle da distribuidora sobre os postos revendedores e na fidelização dos clientes à marca.

Finalmente, no caso de eventuais desvios durante a cadeia, a solução 
ainda possibilita o rastreio e identificação das descontinuidades e de seus autores. Se não, em tempo real, com muita proximidade do evento, uma vez que diversos pontos de controle são implementados tanto na entrega quanto na revenda ao consumidor final.

Fica claro que a blockchain se torna uma poderosa aliada da sociedade como ferramenta de transparência e aumento de confiança generalizada nas relações pessoais e contratuais.

No presente estudo, a implantação da solução proposta não apresenta grandes barreiras tecnológicas, uma vez que as principais distribuidoras já possuem sistemas digitais para controle de venda, estoque e distribuição dos combustíveis vendidos. Da mesma forma, estas também possuem sistema de recompensa e fidelização de clientes através da distribuição de pontos de fidelidade com valor financeiro. A implantação da solução proposta estaria totalmente integrada aos sistemas já existentes nas distribuidoras.

Vale ressaltar, entretanto, a fragilidade existente na cadeia de distribuição no recebimento de produto e validação do volume no ato de entrega do combustível do transportador ao posto de combustíveis. Esta fragilidade de validação de volume já existe na cadeia atual e, apesar dos mecanismos de controle existentes na solução em blockchain, continuará, em certo grau, sendo um ponto de fragilidade na nova solução. A validação desses volumes, na maioria dos casos, depende da intervenção manual dos transportadores e dos funcionários do posto e, se estes tiverem interesses individuais no controle equivocado do volume recebido, informações erradas podem ser inseridas na blockchain. Apesar disso, este erro intencional introduzido na blockchain não poderá persistir por muito tempo sem ser identificado nos sucessivos controles de volumes e vendas. $\mathrm{O}$ ato falho será identificado e rastreado até sua origem.

Tirando este ponto de fragilidade, que não é novo, quaisquer outras oportunidades de adulteração da qualidade ou do volume de produto vendido poderão ser facilmente rastreadas através do controle de volume digital presente na blockchain. Ademais, o próprio sistema de transparência e os smart contracts terão papel de inibidores do comportamento oportunista aos participantes da cadeia. A chance de impunidade cairá significativamente, o que consequentemente reduzirá as brechas para oportunismos do envolvidos.

Conclui-se, portanto, que a solução proposta em blockchain pode beneficiar a cadeia de distribuição de combustíveis trazendo maior transparência e segurança para as transações e inibindo significativamente as possiblidades de oportunismos dos envolvidos. 


\section{1 Recomendações para futuros trabalhos}

Como recomendação para futuros trabalhos vê-se tanto a possiblidades do aprofundamento da solução proposta neste trabalho como a ampliação do horizonte de cobertura dela.

O primeiro caminho, talvez o mais evidente, seria o aprofundamento do atual trabalho nos detalhes técnicos acerca da solução em Blockchain, fazendose necessário um estudo sobre o Hyperledger, a estrutura de dados a ser adotada e eventuais limitações à sua implantação, notadamente no que concerne a integração deste com os sistemas existentes nas distribuidoras. Também seria necessário um estudo acerca da compatibilização da solução dentro do Hyperledger com os sistemas de recompensa existentes nas distribuidoras, uma vez que as blockchains privadas não possuem os mesmos sistemas de criptoativos para a recompensa dos participantes, como as blockchains públicas.

A segunda possibilidade seria a ampliação do escopo do presente trabalho através do estudo de uma solução em blockchain consorciada. Este consórcio seria capaz de envolver mais do que uma distribuidora, englobando eventualmente todo o setor de distribuição, inclusive agentes de fiscalização e reguladores. Esta proposta poderia ser implantada por algum órgão governamental de controle ou por um coletivo organizado de empresas que tivessem o interesse de beneficiar toda a cadeia. Do modo como está apresentado no presente trabalho, a solução serviria para a melhora da cadeia de distribuição de uma distribuidora somente, podendo servir inclusive como vantagem competitiva para ela, reduzindo seus custos transacionais. 


\section{6 Referências bibliográficas}

AGÊNCIA NACIONAL DO PETRÓLEO - ANP. Portaria ANP n¹16/2000, 2000. Disponível em: <https://atosoficiais.com.br/anp/portaria-tecnica-n-116-2000->

AGÊNCIA NACIONAL DO PETRÓLEO - ANP. Resolução ANP nº 42 de 24/11/2004, 2004. Disponivel em: <https://atosoficiais.com.br/anp/resolucao-n-42-2004-estabelece-aespecificacao-para-a-comercializacao-de-biodiesel-que-podera-ser-adicionado-ao-oleodiesel-na-proporcao-de-2-em-volume?origin=instituicao\&q=42>

AHLUWALIA, S.; MAHTO, R. V.; GUERRERO, M. Blockchain technology and startup financing: A transaction cost economics perspective. Technological Forecasting and Social Change, v. 151, n. December 2019, p. 119854, 2020.

AJAO, L. A. et al. Crypto Hash Algorithm-Based Blockchain Technology for Managing Decentralized Ledger Database in Oil and Gas Industry. J, v. 2, n. 3, p. 300-325, 2019.

ATLAM, H. F.; WILLS, G. B. Technical aspects of blockchain and loT. 1. ed. [s.I.] Elsevier Inc., 2019. v. 115

BEHNKE, K.; JANSSEN, M. F. W. H. A. Boundary conditions for traceability in food supply chains using blockchain technology. International Journal of Information Management, v. 52, n. June 2019, p. 101969, 2020.

BENTOV, I.; GABIZON, A.; MIZRAHI, A. Cryptocurrencies without proof of work. Lecture Notes in Computer Science (including subseries Lecture Notes in Artificial Intelligence and Lecture Notes in Bioinformatics), v. 9604 LNCS, p. 142-157, 2016.

CAICT. Blockchain White Paper, 2018.

CATALINI, C.; S.GANS, J. Some Simple Economics of Blockchain. Journal of Chemical Information and Modeling, p. 1-39, 2019.

CHEN, E. An approach for Improving Transparency and Traceability of Industrial Supply Chain With Blockchain Technology, 2016.

CHEN, Y. Blockchain tokens and the potential democratization of entrepreneurship and innovation. Business Horizons, v. 61, n. 4, p. 567-575, 2018.

DA SILVA MOMO, F.; SCHIAVI, G. S.; BEHR, A. Business models and blockchain: What can change? Americas Conference on Information Systems 2018: Digital Disruption, AMCIS 2018, p. 228-248, 2018.

DAVIDSON, S.; DE FILIPPI, P.; POTTS, J. Economics of Blockchain. SSRN Electronic Journal, p. 1-23, 2016.

DOGO, E. M. et al. Blockchain and Internet of Things-Based Technologies for Intelligent Water Management System. p. 129-150, 2019. 
EMPRESA DE PESQUISA ENERGÉTICA - EPE. Panorama do Refino e da Petroquímica no Brasil. p. 73, 2018.

EVANS, D. S. Economic Aspects of Bitcoin and Other Decentralized Public-Ledger Currency Platforms. SSRN Electronic Journal, v. 685, n. April, 2014.

GALVEZ, J. F.; MEJUTO, J. C.; SIMAL-GANDARA, J. Future challenges on the use of blockchain for food traceability analysis. TrAC - Trends in Analytical Chemistry, v. 107, p. 222-232, 2018.

GONÇALVES, V. P.; GUERRA, L. A Agência Nacional do Petróleo e o Combate à Fraude dos Combustíveis. 2012.

GOVERNO FEDERAL DO BRASIL. LEI Nº 13.576, DE 26 DE DEZEMBRO DE 2017, 2017. Disponível em: <http://www.planalto.gov.br/ccivil_03/_ato20152018/2017/lei/l13576.htm>

HIRBLI, T. Palm Oil traceability: Blockchain meets supply chainMIT, 2018. Disponível em: <https://dspace.mit.edu/bitstream/handle/1721.1/117800/1051223547-

MIT.pdf?sequence $=1>$

HYPERLEDGER. An Introduction to Hyperledger, 2018.

HYPERLEDGER. What is Hyperledger Fabric? Disponível em: <https://hyperledgerfabric.readthedocs.io/en/latest/blockchain.html\#what-is-hyperledger-fabric $>$. Acesso em: 5 dez. 2020a.

HYPERLEDGER. Use Hyperledger. Disponível em: <https://www.hyperledger.org/use>. Acesso em: 30 jan. 2021b.

KAMILARIS, A.; FONTS, A.; PRENAFETA-BOLD'Y, F. X. The rise of blockchain technology in agriculture and food supply chains. Trends in Food Science and Technology, v. 91, n. July, p. 640-652, 2019.

KSHETRI, N. 1 Blockchain's roles in meeting key supply chain management objectives. International Journal of Information Management, v. 39, n. December 2017, p. 80-89, 2018.

$\mathrm{LU}, \mathrm{H}$. et al. Blockchain technology in the oil and gas industry: A review of applications, opportunities, challenges, and risks. IEEE Access, v. 7, p. 41426-41444, 2019.

MINISTÉRIO DO MEIO AMBIENTE - MMA. LEI N 8.723 DE 28 DE OUTUBRO DE 1993, 1993. Disponível em: <http://www.planalto.gov.br/ccivil_03/leis/l8723.htm>

NAKAMOTO, S. Bitcoin: A Peer-to-Peer Electronic Cash System. SSRN Electronic Journal, p. 1-9, 2008.

PAHL, C.; EL IOINI, N.; HELMER, S. A decision framework for blockchain platforms for iot and edge computing. IoTBDS 2018 - Proceedings of the 3rd International Conference on Internet of Things, Big Data and Security, v. 2018-March, n. loTBDS 2018, p. 105113, 2018.

RAVAL, S. Decentralized Applications: Harnessing Bitcoin's Blockchain Technology. Sebastopol: O'Reilly Media, Inc., 2016. 
SAVELYEV, A. Contract law 2.0: 'Smart' contracts as the beginning of the end of classic contract law. Information and Communications Technology Law, v. 26, n. 2, p. 116-134, 2017.

SCHATSKY, D.; MURASKIN, C. Beyond bitcoin : Blockchain is coming to disrupt your industry. Deloitte University Press, p. 1-27, 2015.

SCHMIDT, C. G.; WAGNER, S. M. Blockchain and supply chain relations: A transaction cost theory perspective. Journal of Purchasing and Supply Management, v. 25, n. 4, p. 100552, 2019.

SEIJAS, P. L.; THOMPSON, S.; MCADAMS, D. Scripting smart contracts for distributed ledger technology. Lecture Notes in Computer Science (including subseries Lecture Notes in Artificial Intelligence and Lecture Notes in Bioinformatics), v. 10323 LNCS, p. 631-632, 2016.

SOARES, A. C.; LEAL, J. E.; AZEVEDO, I. R. DE. Diagnóstico da rede de distribuição de derivados de petróleo no Brasil e sua representação em um SIG. p. 1-8, 2003.

SOARES, S. DE S. S.; SAES, M. S. M. Distribuição de combustível no estado de São Paulo: estruturas de governança e mecanismos complementares de coordenação. Revista de Administração, v. 50, n. 2, p. 241-253, 2015.

SWAN, M. Blockchain: Blueprint for a New Economy. [s.I.] O'Reilly Media, Inc., 2015.

SZABO, NI. Formalizing and Securing Relationships on Public Networks. First Monday, v. 2, n. 9, 1997.

TAPSCOTT, D.; TAPSCOTT, A. Bockchain Revolution. New York: Penguin, 2016.

THE ECONOMIST. The trust machine. The Economist, 2015.

TIAN, F. An agri-food supply chain traceability system for China based on RFID \& blockchain technology. 2016 13th International Conference on Service Systems and Service Management, ICSSSM 2016, 2016.

TIAN, F. A supply chain traceability system for food safety based on HACCP, blockchain \& Internet of things. 14th International Conference on Services Systems and Services Management, ICSSSM 2017 - Proceedings, 2017.

TREIBLMAIER, $\mathrm{H}$. The impact of the blockchain on the supply chain: a theory-based research framework and a call for action. Supply Chain Management, v. 23, n. 6, p. 545559, 2018.

VILLACRESES PONCE, A. G. Blockchain application for the supply chain of the ecuadorian oil industry, 2020.

ZHAO, J. L.; FAN, S.; YAN, J. Overview of business innovations and research opportunities in blockchain and introduction to the special issue. Financial Innovation, v. 2, n. 1, p. 17, 2016. 